\title{
The European Infrasound Bulletin
}

\author{
Christoph Pilger, ${ }^{1}$ (D Lars Ceranna, ${ }^{1}$ J. Ole Ross, ${ }^{1}$ Julien Vergoz, ${ }^{2}$ Alexis Le Pichon, ${ }^{2}$ Nicolas Brachet, ${ }^{2}$ \\ Elisabeth Blanc, ${ }^{2}$ Johan Kero, ${ }^{3}$ Ludwik Liszka, ${ }^{3}$ Steven Gibbons, ${ }^{4}$ Tormod Kvaerna, ${ }^{4}$ Sven Peter Näsholm, ${ }^{4}$ \\ Emanuele Marchetti, ${ }^{5}$ Maurizio Ripepe,${ }^{5}$ Pieter Smets, ${ }^{6}$ Laslo Evers, ${ }^{6}$ Daniela Ghica, ${ }^{7}$ Constantin Ionescu, ${ }^{7}$ \\ Tereza Sindelarova, ${ }^{8}$ Yochai Ben Horin, ${ }^{9}$ and Pierrick Mialle ${ }^{10}$
}

\begin{abstract}
The European Infrasound Bulletin highlights infrasound activity produced mostly by anthropogenic sources, recorded all over Europe and collected in the course of the ARISE and ARISE2 projects (Atmospheric dynamics Research InfraStructure in Europe). Data includes high-frequency $(>0.7 \mathrm{~Hz})$ infrasound detections at 24 European infrasound arrays from nine different national institutions complemented with infrasound stations of the International Monitoring System for the Comprehensive NuclearTest-Ban Treaty (CTBT). Data were acquired during 16 years of operation (from 2000 to 2015) and processed to identify and locate $~ 48,000$ infrasound events within Europe. The source locations of these events were derived by combining at least two corresponding station detections per event. Comparisons with ground-truth sources, e.g., Scandinavian mining activity, are provided as well as comparisons with the CTBT Late Event Bulletin (LEB). Relocation is performed using ray-tracing methods to estimate celerity and back-azimuth corrections for source location based on meteorological wind and temperature values for each event derived from European Centre for Medium-range Weather Forecast (ECMWF) data. This study focuses on the analysis of repeating, man-made infrasound events (e.g., mining blasts and supersonic flights) and on the seasonal, weekly and diurnal variation of the infrasonic activity of sources in Europe. Drawing comparisons to previous studies shows that improvements in terms of detection, association and location are made within this study due to increasing the station density and thus the number of events
\end{abstract}

1 BGR (Federal Institute for Geosciences and Natural Resources), Hannover, Germany. E-mail: christoph.pilger@bgr.de

2 CEA (Commissariat à l'Energie Atomique et aux Energies Alternatives), Paris, France.

3 IRF (Institutet för rymdfysik), Kiruna, Sweden.

4 NORSAR (Stiftelsen Norwegian Seismic Array), Kjeller, Norway.

5 UNIFI (Universita degli Studi Di Firenze), Florence, Italy.

6 KNMI (Koninklijk Nederlands Meteorologisch Instituut), De Bilt, The Netherlands.

7 NIEP (National Institute for Earth Physics), Măgurele, Romania.

8 UFA (Ustav Fyziky Atmosfery), Prague, Czech Republic.

9 SOREQ (Soreq Nuclear Research Center), Yavne, Israel.

10 CTBTO (Comprehensive Nuclear-Test-Ban Treaty Organization), Vienna, Austria. and determined source regions. This improves the capability of the infrasound station network in Europe to more comprehensively estimate the activity of anthropogenic infrasound sources in Europe.

Key words: Infrasound, anthropogenic sources, European bulletin, ARISE.

\section{Introduction}

Infrasound is low-frequency sound below the threshold of human hearing, i.e., below $20 \mathrm{~Hz}$. Various sources either of natural or of anthropogenic origin generate sound with infrasonic frequency components (Campus and Christie 2010; Hedlin et al. 2012), mostly when explosive or eruptive processes are involved. Consequently, rocket launches, military and industrial blasts, volcanic activity and meteoroid entries are among the strongest sources of infrasound (Mc Laughlin et al. 2000; Stevens et al. 2002; Ceranna et al. 2009; Matoza et al. 2011; Marchetti et al. 2013; Le Pichon et al. 2013; Pilger et al. 2015). Other, less intense infrasound signatures are generated by supersonic flights, microbaroms, severe weather, mining activity and wind turbines (Le Pichon et al. 2002; Garcés et al. 2004; Sindelarova et al. 2009; Gibbons et al. 2015a; Pilger and Ceranna 2017). This study focuses on anthropogenic infrasound signatures and the main interest therefore is on high-frequency (HF) infrasound above $0.7 \mathrm{~Hz}$. Sources with lower dominant frequencies, e.g., mountain waves, microbaroms, earthquakes, volcanoes and meteoroids are mostly suppressed by this choice. 
Infrasound can be detected by very sensitive microphones and microbarometers, which are pressure sensors specialized to detect small differential pressure variations in the sub-pascal (microbar) range (Ponceau and Bosca 2010). Typically, microbarometers are arranged together with wind noise reduction systems in an array configuration of at least three sensors (Christie and Campus 2010; Walker et al. 2010). Using arrays allows for the estimation of backazimuth direction and trace velocity of coherent infrasound signals recorded at an infrasound array, together with frequency and amplitude parameters (Brachet et al. 2010; Garcés 2013). The identification of infrasound signatures thus estimated to originate from the same source event at two or more stations, then allows for a basic localization of the source by intersecting the two (or more) back-azimuth direction estimates.

This study considers a total of 24 infrasound arrays in and around Europe to detect and to locate infrasound events mostly from anthropogenic sources. Infrasound recorded by stations from nine different national institutions and the International Monitoring System (IMS) of the Comprehensive Nuclear-Test-Ban Treaty Organization (CTBTO, http://ctbto.org/, last access March 2018) is used to generate a European Infrasound Bulletin (EIB) of HF-infrasound activity during 16 years (2000-2015) of operation. Infrasound recordings and data contributions by international partners were collected in the course of the Atmospheric dynamics Research InfraStructure in Europe project (ARISE, http://ariseproject.eu/, last access March 2018) funded by the EU FP7 (ARISE1 2012-2014) and Horizon 2020 (ARISE2 2015-2018) programmes.

This study follows up the work initiated by Le Pichon et al. (2008), wherein a total number of seven stations were considered and the duration of observations was from 2000 to 2006 . For this study, the time duration is more than doubled and the number of stations is more than tripled, which results in an increase in the number of detected infrasound events by approximately a factor of ten. Furthermore, this study improves the following: (1) the source localization of the previous study by using ray-tracing methods, climatologies and analysis data from numerical weather prediction models for realistic atmospheric background conditions and infrasound propagation modeling is obtained (Garcés et al. 1998; Drob et al. 2003; Pilger et al. 2013); (2) the seasonal and diurnal variations of the sources and detected infrasonic activity are highlighted in greater detail; (3) the findings are compared with ground-truth information, e.g., from explosions identified using seismic data in various seismo-acoustic studies (Evers and Schweitzer 2011; Gibbons et al. 2015a; Ghica et al. 2016).

Section 2 provides information on the contributing stations and the data analyzed in this study. Section 3 describes the methods for the detection, localization and estimation of infrasound source activity in Europe. Section 4 presents and discusses the results of this study in terms of source regions, comparison to ground-truth and time-dependent variations of the infrasound activity. Section 5 concludes this study and provides a short outlook.

\section{Stations and Data}

This study considers 24 stations within and around Europe which contribute to the European Infrasound Bulletin. Seven of these are permanent infrasound arrays of the CTBT IMS (I18DK, I26DE, I31KZ, I37NO, I42PT, I43RU, I48TN), 1 is a temporary installation (I66TN) and 16 further stations are permanent national infrasound arrays operated by partners of the ARISE community (see Fig. 1). All infrasound arrays consist of at least three array elements and thus allow trace velocity and back-azimuth estimations of incoming coherent infrasound signatures.

The stations that participate in the European Infrasound Bulletin study feature different array configurations and instrumentation (see Gibbons et al. 2015b for a representation of different IMS station configurations). Table 1 provides some basic information on the specification of each IMS and national partner's infrasound array used in this study. 


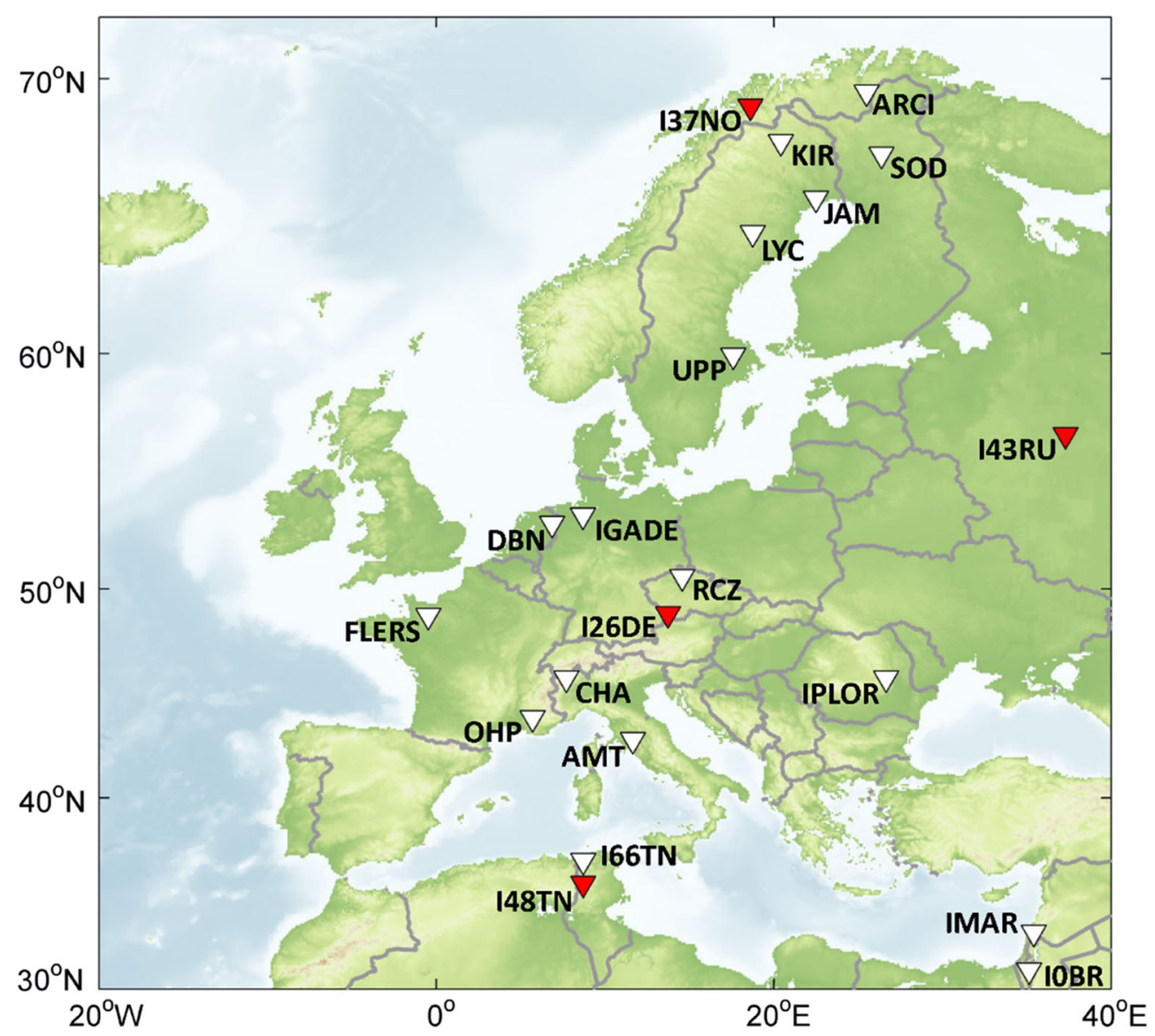

Figure 1

Infrasound arrays in and around Europe contributing to the European Infrasound Bulletin. Stations beyond the limits of the shown map that also contribute to the bulletin are I18DK (on Greenland), I31KZ (in Kazakhstan) and I42PT (on the Azores). Permanent IMS stations are shown in red, while further national arrays and temporary installations are shown in white

The data that were collected to form the European Infrasound Bulletin are presented in Fig. 2. This dataset consists of three stages of data collection and processing: (1) data from 2000 to 2008 are available from the stations originally contributing to the Le Pichon et al. (2008) study, (2) data from 2008 to 2012 consisting of additional arrays brought together from ARISE partners and IMS stations in the preparation phase of the ARISE project and (3) data from 2012 to 2016 collected from new temporary stations operated by ARISE partners and more IMS stations.

Data used within this study are available at different levels, either as raw differential pressure time series for each of the multiple elements of an infrasound array or as detection lists of coherent infrasound events processed using either the Progressive Multi-Channel Correlation (PMCC) method (Cansi 1995) or any similar correlation method applied to the array's data channels (called 'event list' in Table 1) or alternative frequency domain algorithms like the $\mathrm{F}$ detector using Fisher statistics (Evers and Haak 2001; Olson 2004). Each of these datasets is brought together, processed with PMCC, if still containing raw data, pre-filtered, if necessary, and thus harmonized prior to applying the association procedure and relocation. Figure 3 highlights the application of procedures and methods used from raw data and station input to the processed European Infrasound Bulletin. The methods are further described in Sect. 3 . 
Table 1

Information on the infrasound arrays contributing to the European Infrasound Bulletin

\begin{tabular}{|c|c|c|c|c|c|c|}
\hline Station & Coordinates & Partner & Number of elements & Type of instruments & $\begin{array}{l}\text { Data processing } \\
\text { method }\end{array}$ & Aperture \\
\hline I26DE & $\begin{array}{l}48.85^{\circ} \mathrm{N} \\
13.71^{\circ} \mathrm{E}\end{array}$ & BGR & 8 (since 2007 , prior: 5 ) & $\begin{array}{l}\text { MB3 (since } 05 / 2015 \text {, prior: } \\
\text { MB2000/2005) }\end{array}$ & $\mathrm{PMCC}$ & $\begin{array}{l}2 \mathrm{~km} \\
\text { aperture }\end{array}$ \\
\hline IGADE & $\begin{array}{r}53.26^{\circ} \mathrm{N} \\
8.69^{\circ} \mathrm{E}\end{array}$ & BGR & 4 & MB2000 & $\mathrm{PMCC}$ & $\begin{array}{l}0.8 \mathrm{~km} \\
\text { aperture }\end{array}$ \\
\hline KIR & $\begin{array}{l}67.86^{\circ} \mathrm{N} \\
20.42^{\circ} \mathrm{E}\end{array}$ & IRF & 3 & Lidström-microphone & $\mathrm{PMCC}$ & $\begin{array}{l}75 \mathrm{~m} \\
\text { aperture }\end{array}$ \\
\hline SOD & $\begin{array}{l}67.42^{\circ} \mathrm{N} \\
26.39^{\circ} \mathrm{E}\end{array}$ & IRF & 3 & Lidström-microphone & $\mathrm{PMCC}$ & $\begin{array}{l}75 \mathrm{~m} \\
\text { aperture }\end{array}$ \\
\hline JAM & $\begin{array}{l}65.86^{\circ} \mathrm{N} \\
22.50^{\circ} \mathrm{E}\end{array}$ & IRF & 3 & Lidström-microphone & $\mathrm{PMCC}$ & $\begin{array}{l}75 \mathrm{~m} \\
\text { aperture }\end{array}$ \\
\hline LYC & $\begin{array}{l}64.61^{\circ} \mathrm{N} \\
18.75^{\circ} \mathrm{E}\end{array}$ & IRF & 3 & Lidström-microphone & PMCC & $\begin{array}{l}75 \mathrm{~m} \\
\text { aperture }\end{array}$ \\
\hline UPP & $\begin{array}{l}59.93^{\circ} \mathrm{N} \\
17.59^{\circ} \mathrm{E}\end{array}$ & IRF & 3 & Lidström-microphone & $\mathrm{PMCC}$ & $\begin{array}{l}75 \mathrm{~m} \\
\text { aperture }\end{array}$ \\
\hline FLERS & $\begin{array}{l}48.77^{\circ} \mathrm{N} \\
0.47^{\circ} \mathrm{W}\end{array}$ & CEA & 4 & MB2005 & $\mathrm{PMCC}$ & $\begin{array}{l}2.5 \mathrm{~km} \\
\text { aperture }\end{array}$ \\
\hline OHP & $\begin{array}{r}43.93^{\circ} \mathrm{N} \\
5.71^{\circ} \mathrm{E}\end{array}$ & CEA & 4 & MB2005 & PMCC & $\begin{array}{l}1 \mathrm{~km} \\
\text { aperture }\end{array}$ \\
\hline DBN & $\begin{array}{r}52.91^{\circ} \mathrm{N} \\
6.86^{\circ} \mathrm{E}\end{array}$ & KNMI & 6 & KNMI microbarometer & $\mathrm{F}$ detector & $\begin{array}{l}80 \mathrm{~m} \\
\text { aperture }\end{array}$ \\
\hline $\mathrm{RCZ}$ & $\begin{array}{l}50.53^{\circ} \mathrm{N} \\
14.57^{\circ} \mathrm{E}\end{array}$ & UFA & 3 & ISGM03 & PMCC & $\begin{array}{l}0.2 \mathrm{~km} \\
\text { aperture }\end{array}$ \\
\hline IPLOR & $\begin{array}{l}45.84^{\circ} \mathrm{N} \\
26.65^{\circ} \mathrm{E}\end{array}$ & NIEP & 6 & Chaparral Phys. Model 25 & $\mathrm{PMCC}$ & $\begin{array}{l}2.5 \mathrm{~km} \\
\text { aperture }\end{array}$ \\
\hline ARCI & $\begin{array}{l}69.54^{\circ} \mathrm{N} \\
25.51^{\circ} \mathrm{E}\end{array}$ & NORSAR & $\begin{array}{l}9 \text { (since } 10 / 2015 \text {, prior: } 3 \text { until } \\
2010,4 \text { until } 2015 \text { ) }\end{array}$ & $\begin{array}{l}\text { Hyperion IFS-3000 (since 10/2015, } \\
\text { prior: MB2005) }\end{array}$ & $\begin{array}{l}\text { Event list (see } \\
\text { text) }\end{array}$ & $\begin{array}{l}0.5 \mathrm{~km} \\
\text { aperture }\end{array}$ \\
\hline I18DK & $\begin{array}{l}77.50^{\circ} \mathrm{N} \\
69.30^{\circ} \mathrm{W}\end{array}$ & СТВТО & 8 & MB2000 & $\mathrm{PMCC}$ & $\begin{array}{l}1 \mathrm{~km} \\
\text { aperture }\end{array}$ \\
\hline $\mathrm{I} 31 \mathrm{KZ}$ & $\begin{array}{l}50.40^{\circ} \mathrm{N} \\
58.00^{\circ} \mathrm{E}\end{array}$ & СТВТО & 8 & MB2000 & PMCC & $\begin{array}{l}2 \mathrm{~km} \\
\text { aperture }\end{array}$ \\
\hline I48TN & $\begin{array}{r}35.60^{\circ} \mathrm{N} \\
8.70^{\circ} \mathrm{E}\end{array}$ & СТВТО & 7 & MB2000 & PMCC & $\begin{array}{l}2 \mathrm{~km} \\
\text { aperture }\end{array}$ \\
\hline I66TN & $\begin{array}{r}36.78^{\circ} \mathrm{N} \\
8.70^{\circ} \mathrm{E}\end{array}$ & СТВТО & 4 & MB2000 & PMCC & $\begin{array}{l}800 \mathrm{~m} \\
\text { aperture }\end{array}$ \\
\hline I42PT & $\begin{array}{l}37.80^{\circ} \mathrm{N} \\
25.50^{\circ} \mathrm{W}\end{array}$ & СТВТО & 8 & MB2005 & PMCC & $\begin{array}{l}1.5 \mathrm{~km} \\
\text { aperture }\end{array}$ \\
\hline I43RU & $\begin{array}{l}56.70^{\circ} \mathrm{N} \\
37.30^{\circ} \mathrm{E}\end{array}$ & СТВТО & 6 & MB2000 & PMCC & $\begin{array}{l}1.5 \mathrm{~km} \\
\text { aperture }\end{array}$ \\
\hline $\mathrm{I} 37 \mathrm{NO}$ & $\begin{array}{c}69.07^{\circ} \mathrm{N} \\
18.61^{\circ} \mathrm{E}\end{array}$ & NORSAR & 10 & MB2005 (later upgraded to MB3) & PMCC & $\begin{array}{l}2 \mathrm{~km} \\
\text { aperture }\end{array}$ \\
\hline CHA & $\begin{array}{r}45.84^{\circ} \mathrm{N} \\
7.71^{\circ} \mathrm{E}\end{array}$ & UNIFI & 4 & Optimic2180 microphone & $\begin{array}{l}\text { Event list (see } \\
\text { text) }\end{array}$ & $\begin{array}{l}150 \mathrm{~m} \\
\text { aperture }\end{array}$ \\
\hline AMT & $\begin{array}{l}42.87^{\circ} \mathrm{N} \\
11.65^{\circ} \mathrm{E}\end{array}$ & UNIFI & 4 & MB2005 & $\begin{array}{l}\text { Event list (see } \\
\text { text) }\end{array}$ & $\begin{array}{l}1.6 \mathrm{~km} \\
\text { aperture }\end{array}$ \\
\hline IMAR & $\begin{array}{l}33.02^{\circ} \mathrm{N} \\
35.40^{\circ} \mathrm{E}\end{array}$ & SOREQ & 5 & MB2005 & PMCC & $\begin{array}{l}1 \mathrm{~km} \\
\text { aperture }\end{array}$ \\
\hline IOBR & $\begin{array}{l}31.01^{\circ} \mathrm{N} \\
35.13^{\circ} \mathrm{E}\end{array}$ & SOREQ & 4 & MB2000 & PMCC & $\begin{array}{l}4 \mathrm{~km} \\
\text { aperture }\end{array}$ \\
\hline
\end{tabular}




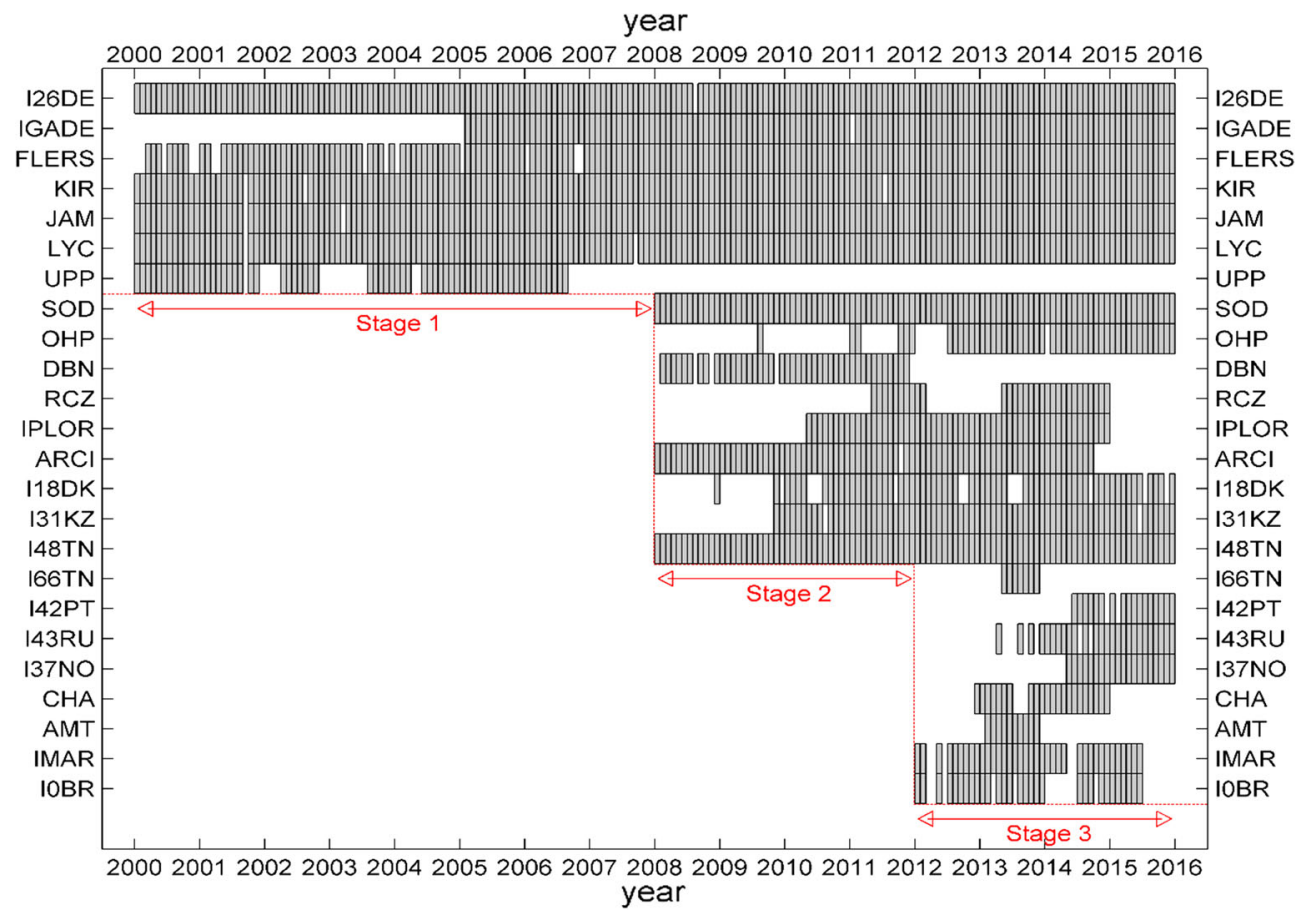

Figure 2

Data availability for the 24 infrasound arrays contributing to the European Infrasound Bulletin. Gray rectangles reflect station data from a station used at least once for the bulletin in the given month. The dashed red line borders outline the three stages of data collection

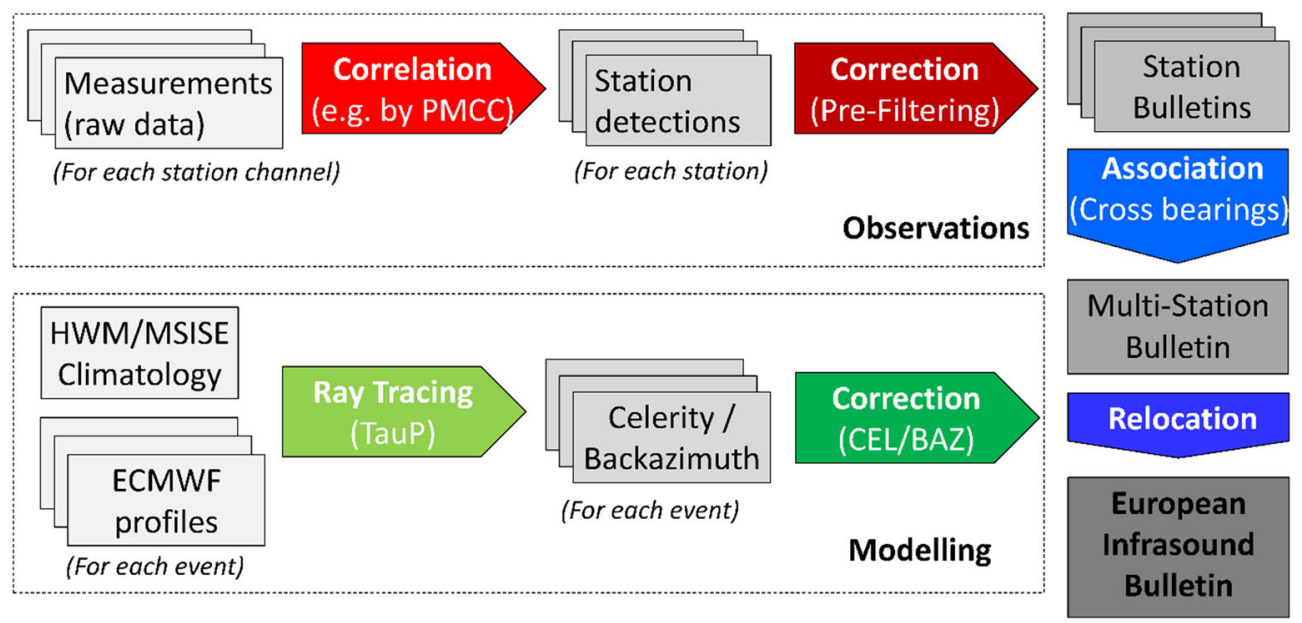

Figure 3

Flowchart describing the methods applied to data from each station and to each bulletin event in the course of this study

\section{Methods}

Multi-channel infrasound raw pressure data is routinely processed for an infrasound station to identify and analyze low-amplitude coherent waves within non-coherent noise. The PMCC method, originally designed for seismic arrays, is based on a progressive study of the correlation functions. It is 
used as a real-time detector for most of the stations within this study. The correlation functions are used to calculate the propagation time of a coherent wave between two array elements and thus to derive direction and velocity information from the resultant time shifts.
Data from the arrays are processed in a high-frequency band covering the $0.7-4 \mathrm{~Hz}$ range. Figure 4 presents the PMCC high-frequency detections for infrasound array $\mathrm{I} 26 \mathrm{DE}$, where the results are shown as a function of back-azimuth and time and color coded with frequency. The symbol size represents PMCC family size, which describes the extent of the
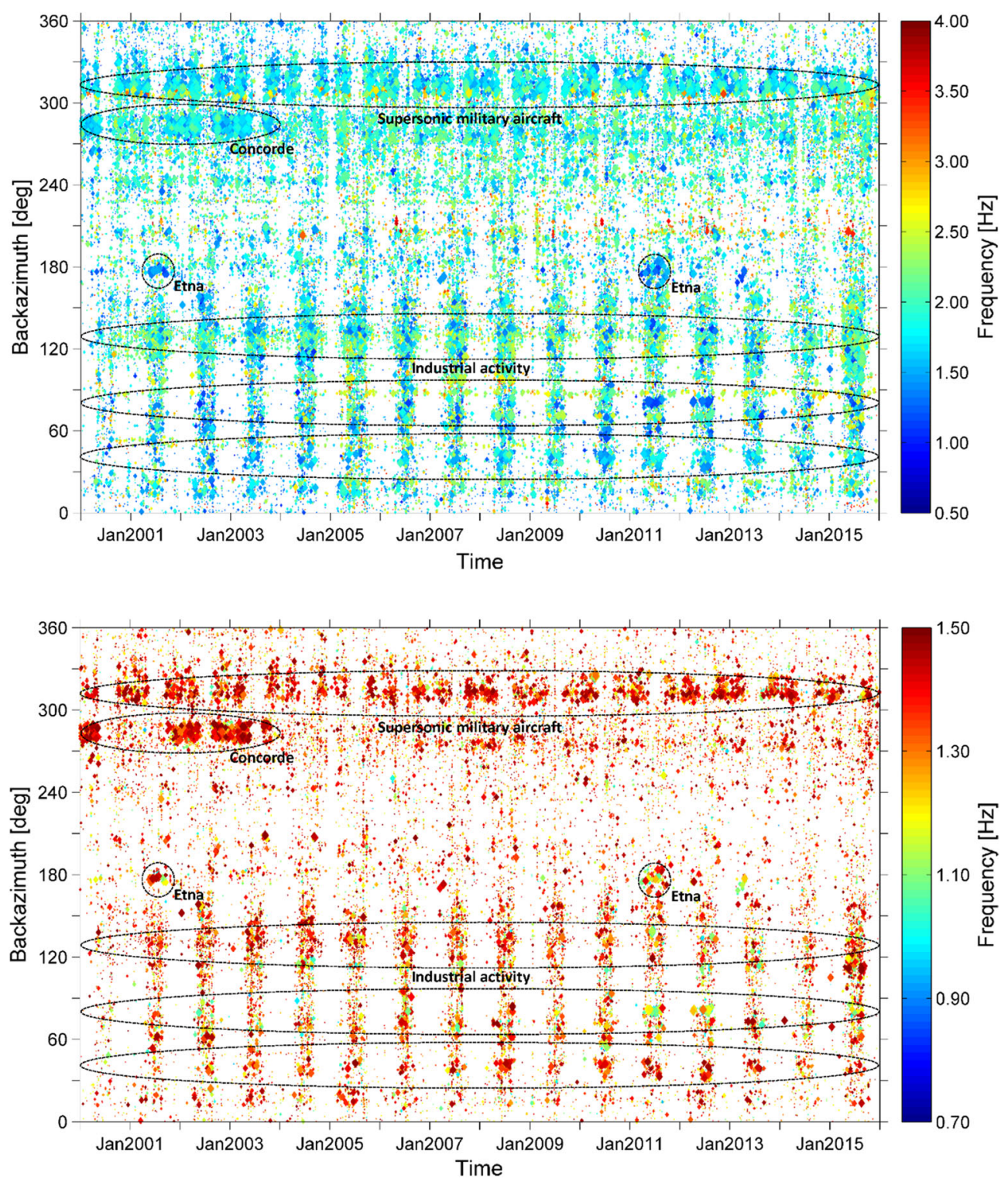

Figure 4

Results of PMCC automatic processing (upper frame) and categorization (lower frame) at IMS station I26DE. Approximately, 370,000 detections (upper frame) are shown as a function of back-azimuth and time, detection mean frequencies are color-coded and their PMCC family size is proportional to the symbol's size. Approximately, 170,000 detections (lower frame) are kept after applying a first cleaning of the bulletin (see text below) 
detections in the time-frequency domain and thus quantifies its event-significant duration and spectral content (see Le Pichon et al. 2010 for further information). 16 years of detections show the typical, semi-annual variation of the prevailing direction of signal arrival due to the semi-annual variation of the stratospheric wind direction, which is westward during summer and eastward during winter in the Northern Hemisphere and vice versa in the Southern Hemisphere (Le Pichon et al. 2005). Figure 4 also highlights various individual and recurrent signatures in the station detections. These for example include the sonic booms of military aircraft (direction $310^{\circ}$ ) and the Concorde flights between 2000 and 2003 (direction $280^{\circ}$ ) as well as Etna activity most prominent in 2001 and 2011 (direction $180^{\circ}$ ) and various sources of northern and eastern European industrial activity during each year's summertime (directions from $0^{\circ}$ to $180^{\circ}$ ).

The detection algorithms used for this study, e.g., PMCC, are very sensitive to coherent signals with even low signal to noise ratio. Therefore, the bulletins contain a very large number of detections, including those from many local sources and long-duration detections which are not of interest to this study. To exclude these signatures with respect to the aims of this study, a categorization procedure is applied in the final stage of the single-station processing to clean the detection bulletins (Le Pichon et al. 2008). This procedure is based on the search for detections with similar characteristics by taking into account azimuth, trace velocity, frequency and time duration parameters. Threshold values are adapted according to the sensitivity of each array to its environment. Detections with dominant frequencies greater than $1.5 \mathrm{~Hz}$ or horizontal trace velocities outside 0.30 to $0.45 \mathrm{~km} / \mathrm{s}$ are likely to be related to local sources or are false detections with unrealistic values of trace velocity. Clusters of long-duration detections of more than $1800 \mathrm{~s}$ are likely to be related to recurrent sources of local signals. Detections derived using Fisher statistics with a Fisher ratio below 2 are also excluded. After applying these procedures, about 50 to $95 \%$ of the detections are filtered out from the bulletins (also see Le Pichon et al. 2008).

The identification and location of events is performed by combining two or more single-station detections with their respective back-azimuth information and onset times that correspond after taking into account the source-to-receiver distances and therefore the travel times. For this estimation, a point source and a uniform atmosphere with a fixed celerity value of $300 \mathrm{~m} / \mathrm{s}$ is assumed, which is a good first approximation to stratospheric arrival celerities. However, it does not reflect actual or realistic atmospheric conditions for all cases. Therefore, a relocation using event-dependent celerity values and a back-azimuth correction is applied later on.

The location of events takes into account all possible associations between the detecting stations, initiated by comparing their cross bearings and iteratively improving the result by using a nonlinear least squares inversion scheme (Coleman and $\mathrm{Li}$ 1996). The same method as described in Le Pichon et al. (2008) is applied to identify the best combination of station detections in case of multiple potential solutions, resulting in the most realistic travel time combination for all detecting stations.

After the bulletins of all individual stations' event detections are combined to produce the common and comprehensive event list (multi-station bulletin, Fig. 3), a relocation procedure is applied to each event of that list. This relocation is based on ray tracing between each of the list's event locations and the stations that detect and define the corresponding event.

One-dimensional ray tracing using the Tau-P method (Garcés et al. 1998) is performed to identify stratospheric propagation paths between source and receivers. Realistic background conditions at the stations are taken into account either relying on MSISE/HWM temperature and wind climatologies (Picone et al. 2002; Drob 2008) or ECMWF analysis data (http://www.ecmwf.int/, last access March 2018). From the ray tracing, a propagation path-dependent celerity can be derived which reflects realistic as well as time- and season-dependent speed of sound and thus celerity conditions instead of the standard value of $300 \mathrm{~m} / \mathrm{s}$ used for the pre-location. Furthermore, a back-azimuth correction value has been derived from the ray tracing, which quantifies how many degrees the propagation angle deviates from a straight source-to-receiver line due to the cross-wind effects accumulated along the propagation 
path (e.g., Smets et al. 2016). If the relocation is unable to predict a realistic source-to-receiver ray path and corresponding travel time, the un-relocated event coordinates and travel time values are used (based on a $300 \mathrm{~m} / \mathrm{s}$ celerity). For the actual study and the ECMWF-based relocation this is the case for $<3 \%$ of the detections.

The benefit of using climatologies as background conditions is that it allows the construction of celerity and back-azimuth correction tables for each station and each direction of propagation independent of actual events. This is quantified in Figs. 5 to 7 by a retina plot for all $360^{\circ}$ directions and for different horizontal trace velocities. Figures $5 \mathrm{a}, \mathrm{b}, 6 \mathrm{a}, \mathrm{b}$ and 7a, b show examples of celerity and back-azimuth variations for the station I26DE, based on MSISE/ HWM values during summer and during winter conditions, and provide the expected values for the average propagation behavior which is propagation to the west in summer and to the east in winter (Drob et al. 2003). The benefit of using ECMWF analysis data instead of climatologies is more realistic atmospheric background conditions for deriving celerity and back-azimuth corrections for each event. Figures $5 \mathrm{c}, \mathrm{d}$ and $6 \mathrm{c}, \mathrm{d}$ show corresponding examples of summer 2012 and winter 2013 profiles for celerity and back-azimuth variations at I26DE. Using ECMWF analysis instead of climatologies also
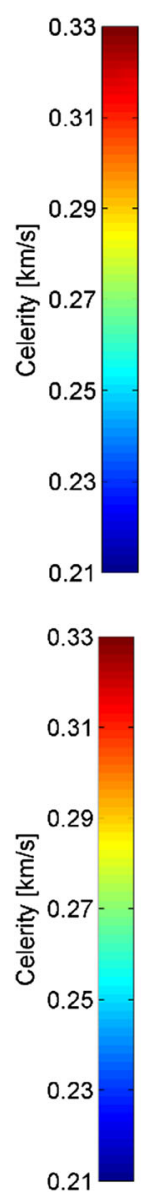
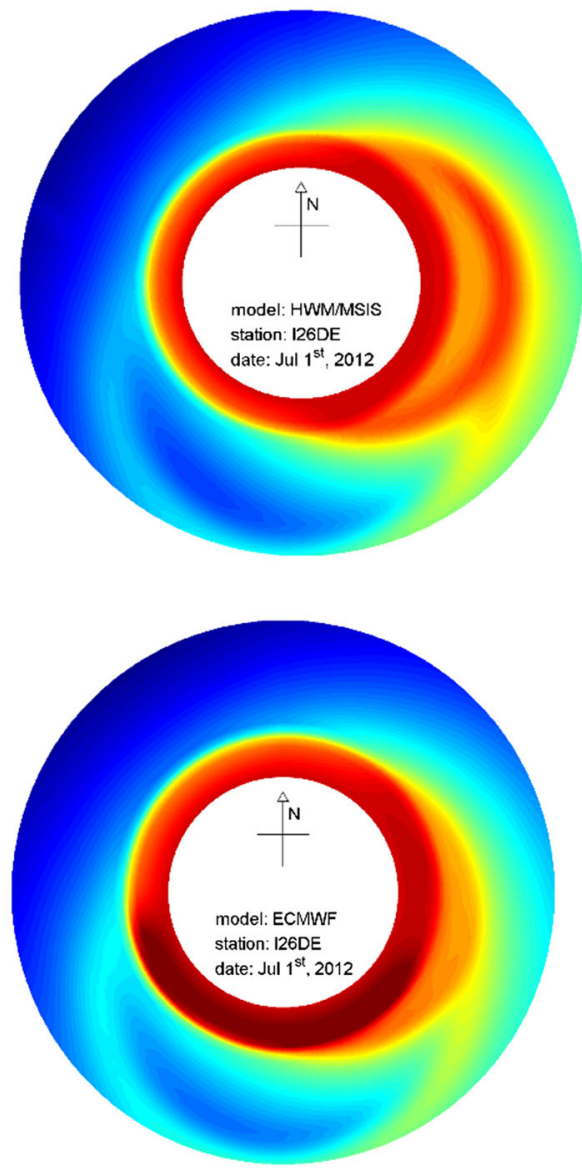
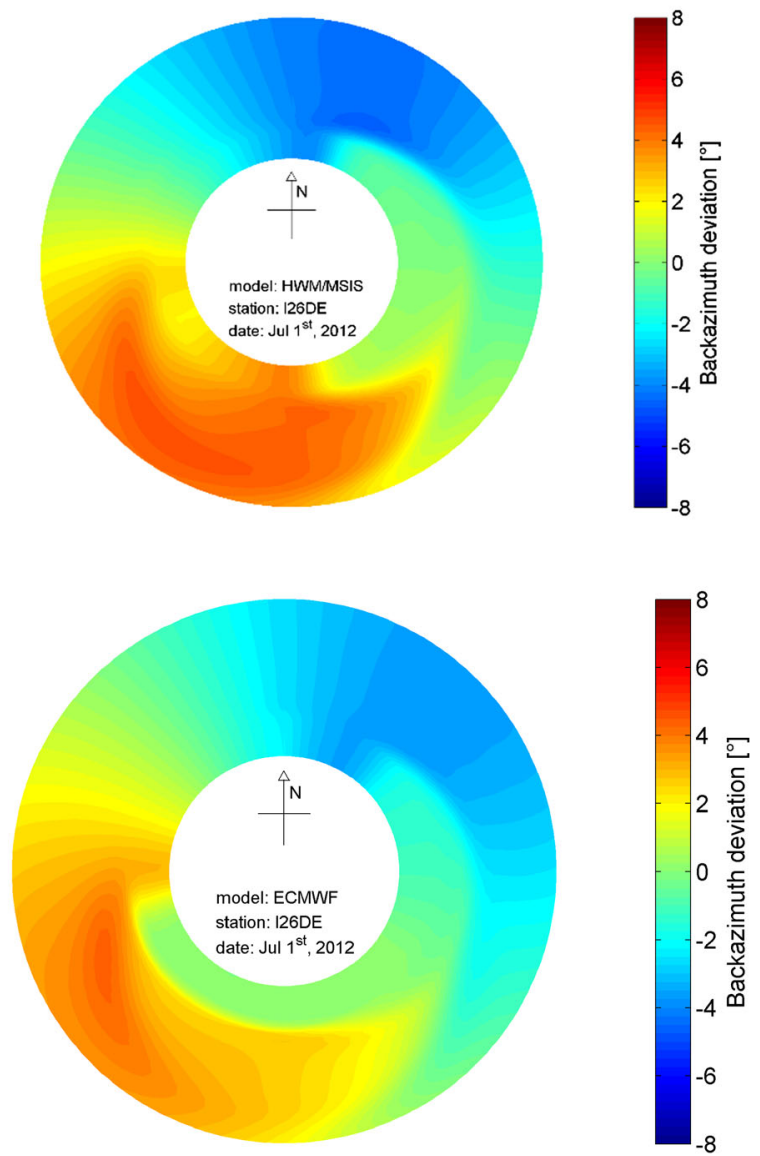

Figure 5

Retina plots showing the $360^{\circ}$ direction dependence of color-coded celerity (left column) and back-azimuth (right column) variations at I26DE during summer conditions (July 1st, 2012), represented by either HWM/MSIS climatologies (upper row) or ECMWF analysis (lower row). North is up, east is to the right, and the horizontal trace velocity is quantified varying from 320 to $420 \mathrm{~m} / \mathrm{s}$ between the inner and outer circle, thus indicating short to long range propagation 

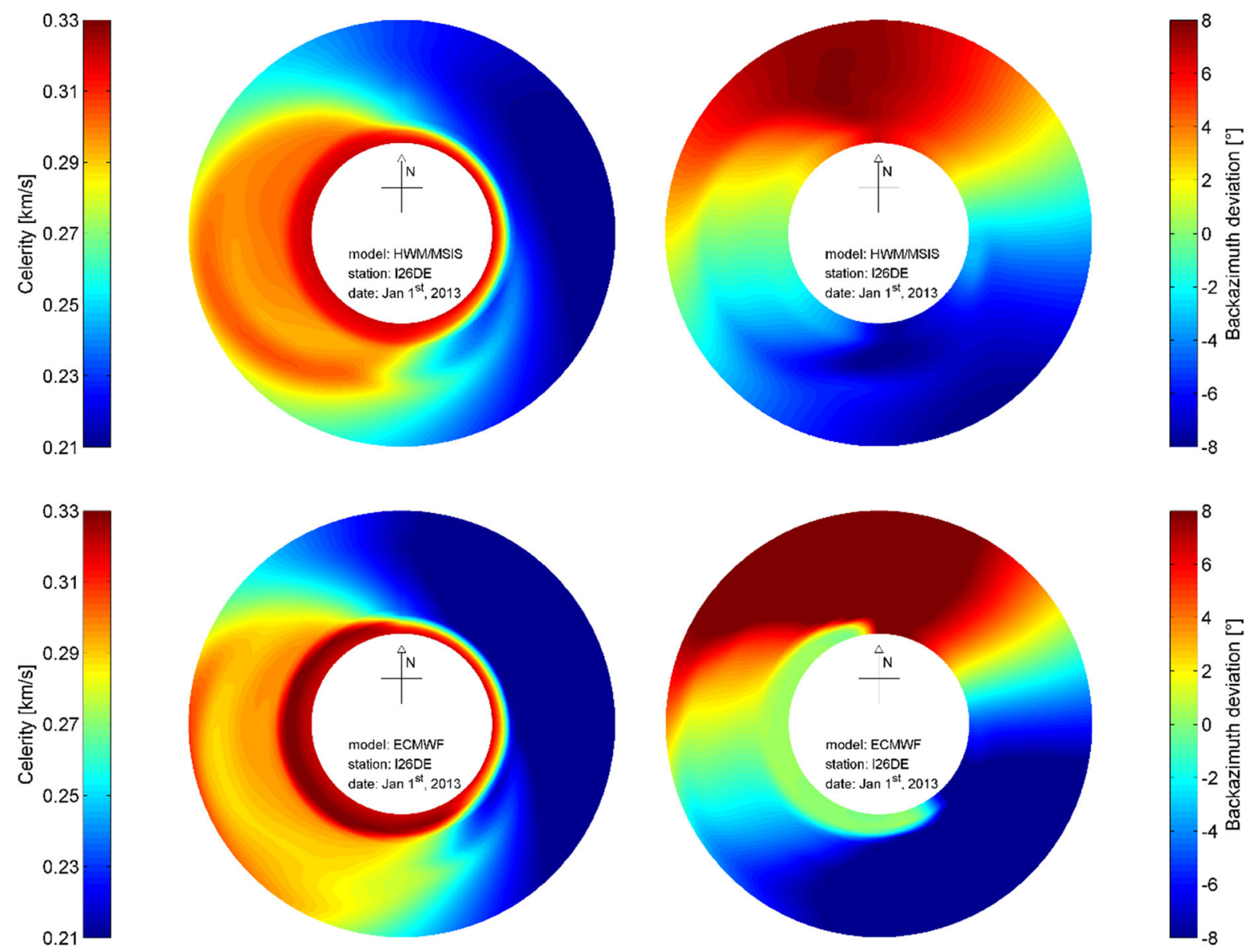

Figure 6

Same as Fig. 5, but for winter conditions (January 1, 2013)

allows deviations from the average atmospheric conditions such as inversion layers or sudden stratospheric warming events (Assink et al. 2014a; Le Pichon et al. 2015) to be taken into account (Fig. 7c, d).

While for the presented typical summer and winter profiles in Figs. 5 and 6 the difference between MSISE/HWM and ECMWF modeling is not very high, it is enormous during a sudden stratospheric warming event happening just 1 week later as shown in Fig. 7. The celerity pattern nearly completely reverses from eastward to westward ducting conditions and the back-azimuth variations change their intensity and flip in the north-south direction.

The approach of using ECMWF instead of climatologies in the event relocation nevertheless depends on the timely availability of ECMWF profiles for each event's time and location and requires much higher computational costs for the relocation.

After the propagation calculations are performed, the corresponding event location is revised according to the relocation with at least two stations taking into account the modified signal travel times and backazimuths. An iterative approach with a nonlinear least-square inversion scheme is again applied. In the case of multiple solutions, the one with the most appropriate celerity values for stratospheric propagation (between 270 and $330 \mathrm{~m} / \mathrm{s}$, see Brown et al. 2002; Negraru et al. 2010) is used. 

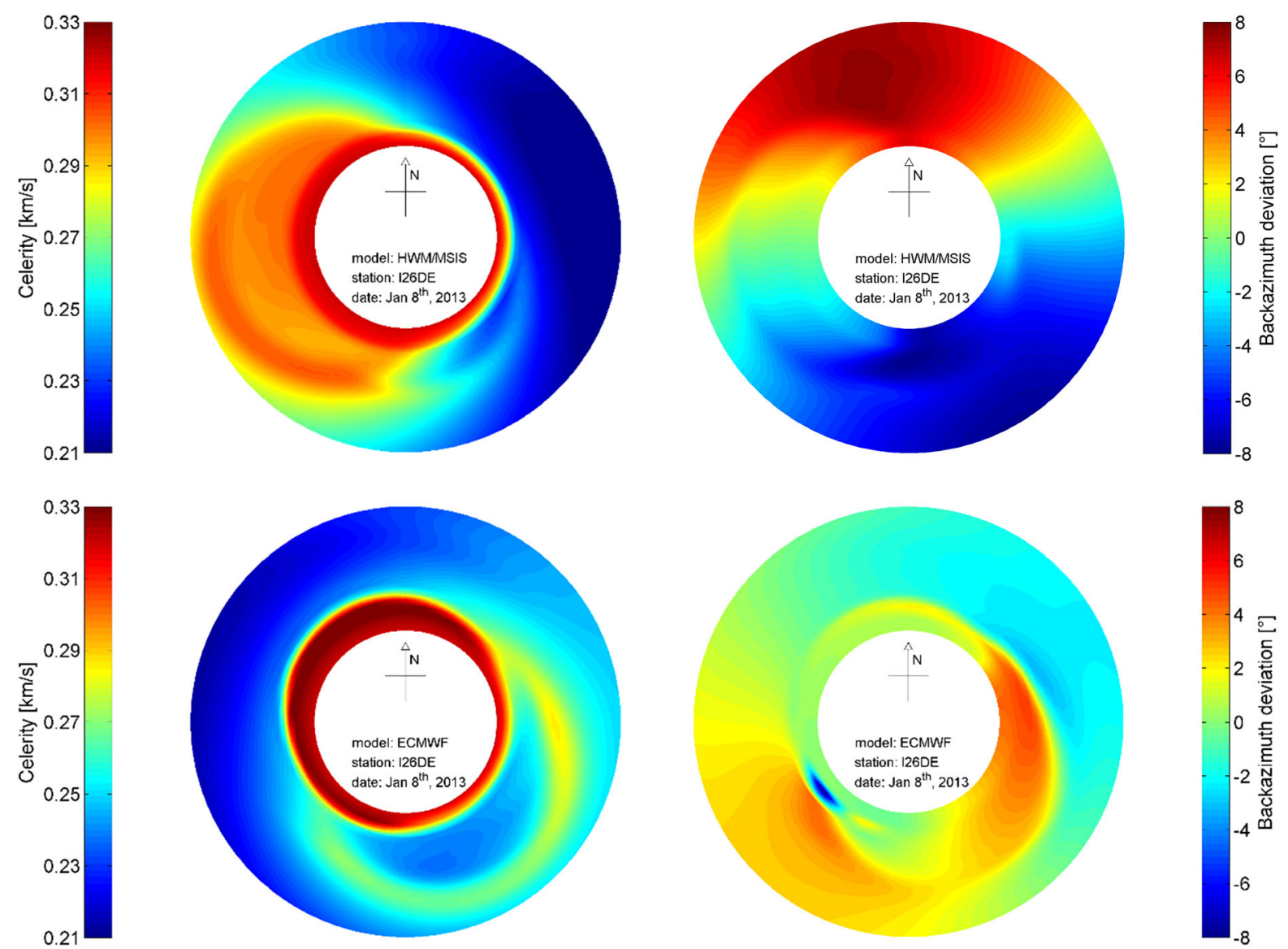

Figure 7

Same as Fig. 5, but for winter conditions during a sudden stratospheric warming event (January 8, 2013)

\section{Results and Discussion}

\subsection{Source Regions and Comparison to Ground Truth}

To generate the European bulletin of infrasound events, cross bearings of two or more of the 24 infrasound arrays are combined and the relocation method using ECMWF profiles is applied for each event as described in Sect. 3.

The benefit of relocation is shown in Fig. 8, where the detections of a local subset of three ground-truth infrasound-generating sources (location derived from aerial photography) is compared before and after relocation. The sources are the PGE GIEK-KWB (PGE Górnictwo i Energetyka Konwencjonalna Oddział Kopalnia Węgla Brunatnego) coal mine near
Bogatynia, Poland, the Skalimex-Grantin granite quarry near Sobótka, Poland and the Lhota Rapotina quarry near Boskovice, Czech Republic.

Before relocation, only two of these three sources are discriminated, as shown in Fig. 8a. After relocation, as seen in Fig. $8 b$, the third source is also detected, which shows that the method to a certain degree focuses distributed source detections and thereby increases the detection density above a certain threshold (here: 5 detections per $0.1^{\circ} \times 0.1^{\circ}$ area). Furthermore, the location accuracy is also slightly increased by applying relocation with realistic atmospheric parameters instead of fixed values. The center of the (colored) detection area for the other two sources moves nearer to the (white star) ground-truth locations after applying relocation. Although the improvements are small for the given 

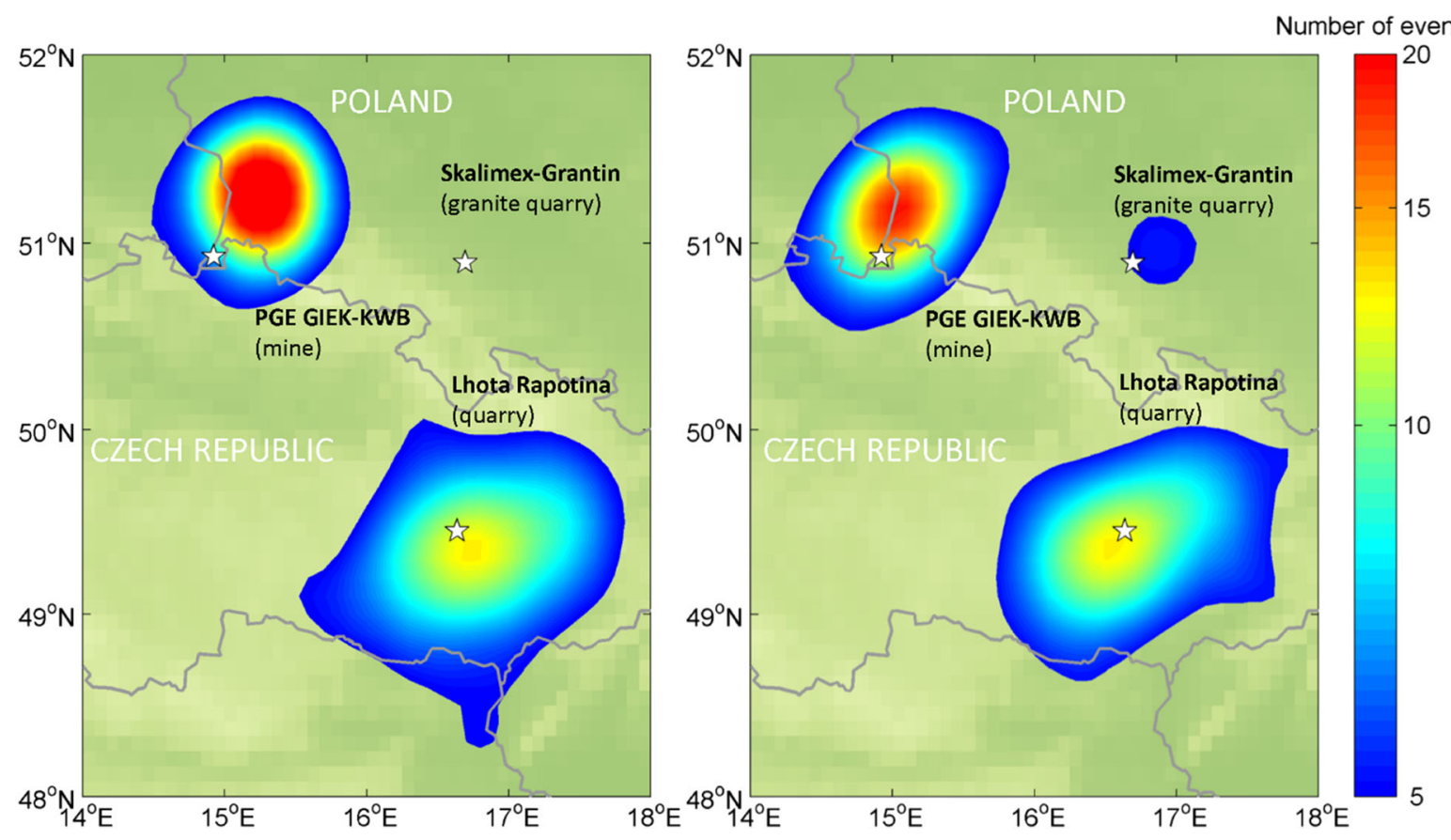

Figure 8

Comparison example between events of the multi-station bulletin before the relocation (left) and events of the EIB after the relocation based on ECMWF (right), in this case for three different anthropogenic sources of mining activity in Poland and the Czech Republic (ground truth locations denoted by white stars). The location and number of events is shown as a color-coded density map, wherein at least five events per $0.1^{\circ} \times 0.1^{\circ}$ area are required to show color information

example and chosen region, they nevertheless highlight that the relocation method leads to improvements in the distance between a source (here a source with ground-truth information) and the center of a cluster of event detections. There is still uncertainty in the location of infrasound events, which will be further discussed in this study.

The result of the complete processing of 24 European stations over a duration of 16 years and the whole area between $30^{\circ} \mathrm{N}$ and $72^{\circ} \mathrm{N}$ as well as $20^{\circ} \mathrm{W}$ and $40^{\circ} \mathrm{E}$ is a dataset with $\sim 48,000$ events of highfrequency infrasound sources within Europe that are detected by two or more arrays (see Fig. 9).

Event clusters in this map are mainly related to anthropogenic origins. These include the industrial activity due to various mining and quarry blasts in Northern Europe, the Concorde flights near London and Paris up to 2003 and other (military) supersonic flights mainly above the North Sea. The event density is highest in Northern Europe since most data are from stations situated in the northern part of the map.
Reduced lower event number thresholds (in the color bar) or adequate filtering as described in Sects. 4.2 and 4.3 also highlights sources in Central and Southern Europe, e.g., the Etna volcano, NATO airbases and other anthropogenic activity there.

The multitude of sources in Northern Europe recorded by a large number of stations is compared with ground-truth surface or near-surface events. Gibbons et al. (2015a) presented a compilation of seismo-acoustic sources in the Fennoscandian region identified from infrasound and seismic recordings. These include a number of quarries and mines as well as military activity in terms of regular ammunition explosions. Figure 10 compares the events derived from the EIB in this region with the areas and ground-truth site locations of the described sources. A clear coincidence between the EIB findings and ground truth can be identified verifying the infrasound signal detection and source relocation method applied here. 


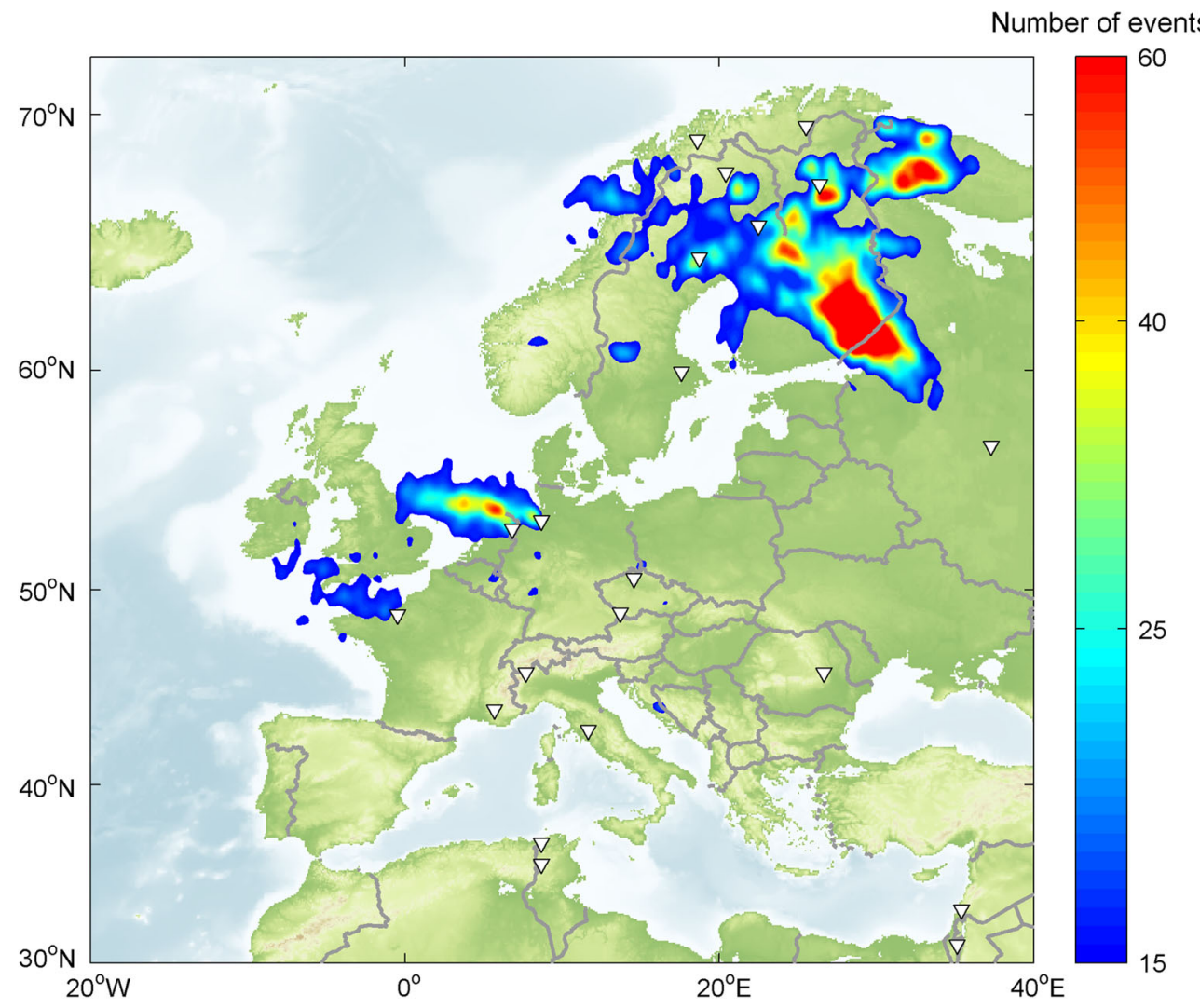

Figure 9

Source regions of high-frequency infrasound derived from the combination of detections from at least two of the 24 infrasound arrays (white triangles). Color-coded event density is described in the same way as in Fig. 8, but for a minimum of 15 events per $0.1^{\circ} \times 0.1^{\circ}$ area

Sources like industrial activity in the Aitik, Laiva, Kemi, Kevitsa, Kostomuksha, Kovdor, Khibiny and Kirkenes mines and quarries correspond very well to infrasound event clusters identified in Fig. 9, while military explosions are also associated fairly well. A large and extended region of infrasound events is shown as a cluster near Lake Ladoga. The high number of events distributed over a large region might result from an area with many different, widely distributed quarries and mines as well as military activity associated with this cluster. A further reason is a higher uncertainty in the location of these events due to (1) two or more stations pointing in nearly the same direction (also see Sect. 4.3 and Nippress and Green 2017) and (2) a lack of back-azimuth resolution at the small aperture IRF infrasound arrays. The KIR, JAM, LYC, UPP and SOD arrays (see Table 1) have an aperture of $75 \mathrm{~m}$ and three elements each, forming a rectangular triangle. The small edge length and thus element-to-element distance make it difficult to precisely estimate the direction of origin for incoming coherent signals when correlating the (only) three elements' time series of these arrays.

When comparing the EIB events of Figs. 9 and 10 with the analyst-reviewed Late Event Bulletin (LEB) of the CTBT International Data Center (IDC), as presented in Fig. 11, good agreement is observed but also numerous differences are identified. Source regions in the North Sea region, in Croatia and in Fennoscandia, are represented accordingly, but additional regions in Eastern Europe and the Mediterranean area are different from those of the EIB.

The major differences in the two event bulletins are explained as follows: 


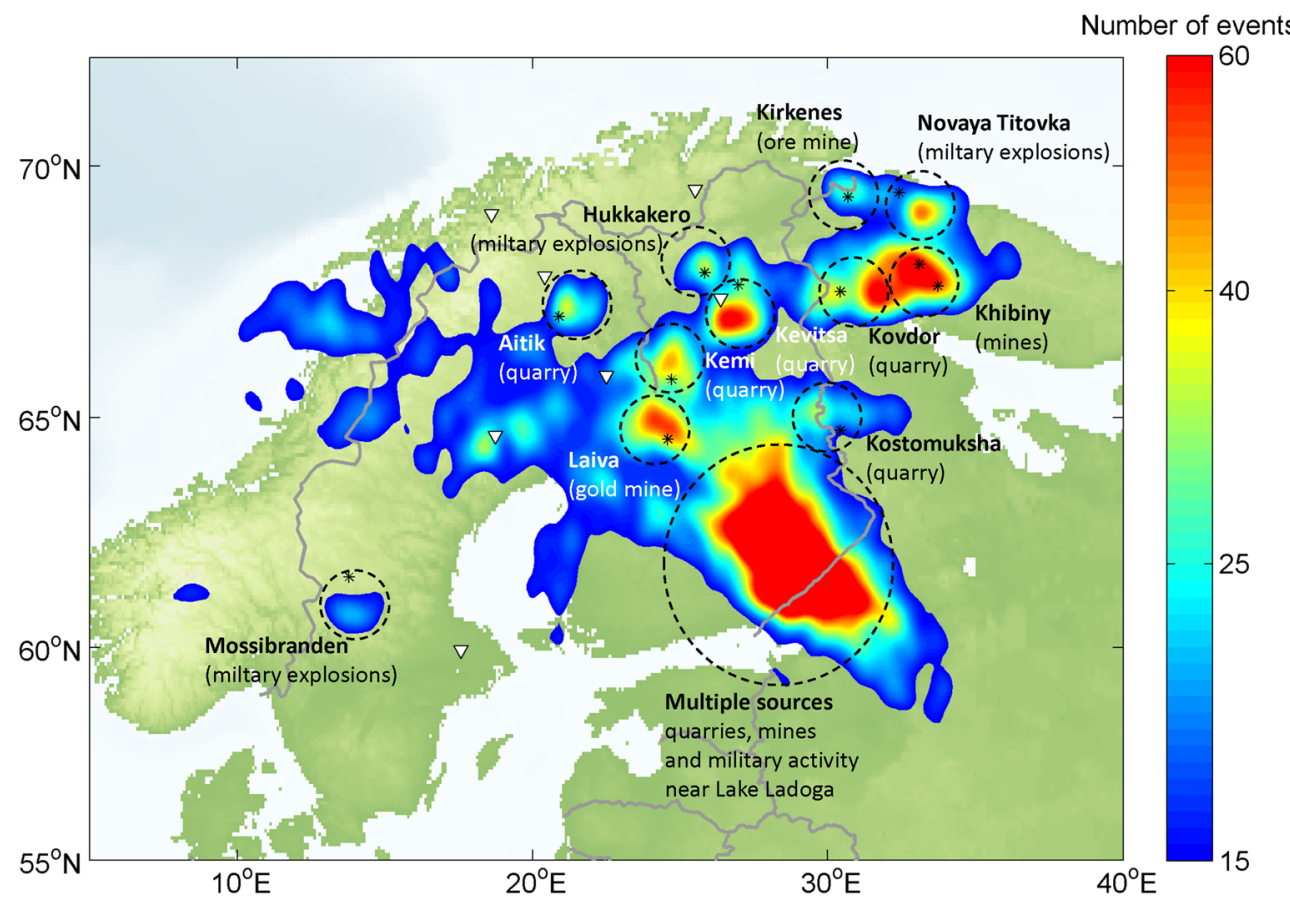

Figure 10

Source regions of high-frequency infrasound (same as Fig. 9) in the Fennoscandian region. Ground-truth location for seismo-acoustic sources from Gibbons et al. (2015a) are marked by asterisk symbols, while dashed circles highlight the association to nearby color-coded infrasound activity

1. The LEB events in this study are derived between January 2010 and November 2017 using and depending on the stations of the global IMS available at the event time, while the current EIB study covers the duration of January 2000 to December 2015 with some stations contributing up to 16 years of data and others only contributing a few months of data. While the EIB consists of 48,000 events, the LEB for this region consists of 4000 events, which is a factor of 12 less in event numbers during about half the time duration.

2. The EIB contains a larger north-south difference in station and data coverage, as already described, and thus strongly highlights event detections in Northern Europe. The LEB on the other hand provides more event detections in Southern Europe and event clusters in Eastern Europe, supported by IMS station detections beyond the shown map borders. This includes detections in the Lake Ladoga region (largest source region in Figs. 9 and 10), but also further clusters south of this region that are not in the EIB due to its sparse data and station coverage at the southern and eastern border of the region observed.

3. Both LEB and EIB require a minimum of two stations to define an event, but the LEB is a completely analyst-reviewed bulletin, while the EIB events result from automatic processing and no analyst review is performed. This reflects a higher uncertainty of the EIB localization compared with the LEB localization. Using a threestation filter for the EIB (similar to the 3-station requirement of the IDC's Reviewed Event Bulletin REB) reduces the number of events and makes the source regions smaller and location more precise, but some source regions are no longer observed, suppressing the number of observed Southern European events even more due to sparse station coverage and data availability.

4. The LEB also includes seismic detections, while the EIB is restricted to pure infrasound detections. 


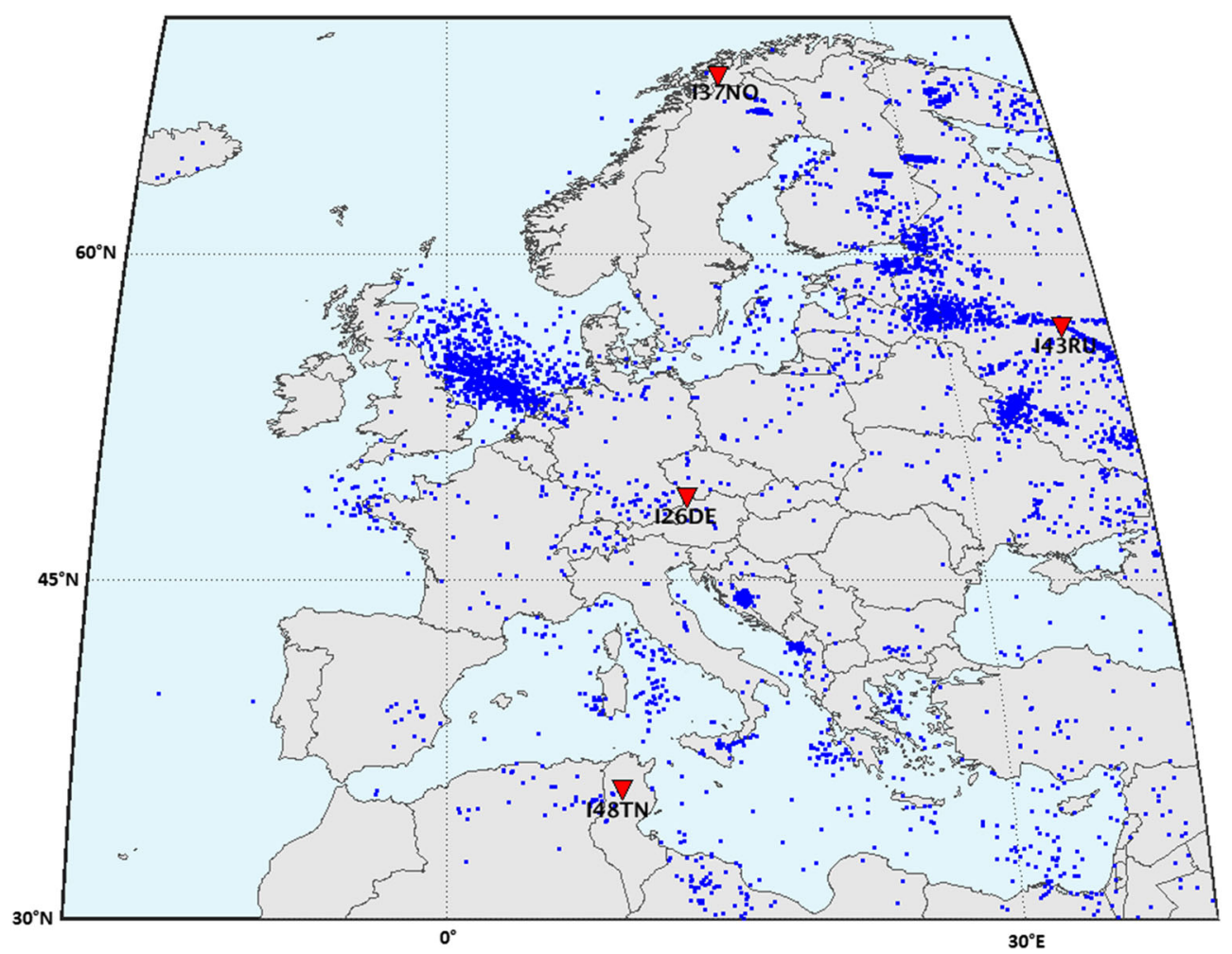

Figure 11

Map of events from the Late Event Bulletin (LEB) of the IDC between 01 January 2010 and 01 November 2017 using the same latitude and longitude frame as shown in Fig. 9. Events are located using at least two stations of the complete available IMS, although only four IMS infrasound stations (red triangles) are in the shown area. The shown events are formed using at least one infrasound detection per event, but they may also contain seismic detections

One of the requirements for this study is that the LEB events used for comparison and shown in Fig. 11 include at least one infrasound array detection per event. 2676 of the LEB events are infrasound-defined events with two or more infrasound stations, 745 LEB events are seismic defined events with two or more infrasound phases involved and the rest are seismic defined events with one additional infrasound phase.

The general comparison between EIB and LEB confirms the large number of infrasound detections in the North Sea area that can be associated with supersonic flights. It furthermore strengthens the consistency of detections of smaller clusters of infrasound activity (e.g., in Croatia, Poland, Finland, Russia and Sicily). It highlights especially in the Fennoscandian region that with a larger number of nearby stations, the identification and localization of a larger number of sources are rendered possible. Identifying and isolating sources and source regions of known previous activity are also relevant for treaty verification purposes, since improved knowledge about the regular infrasound activity in a certain area supports the investigation and identification of irregular activity, such as, e.g., military explosions outside the previously known source regions.

\section{Figure 12}

Seasonal, weekly and diurnal variation of source regions of highfrequency infrasound: a summertime (June to August), b wintertime (December to February), c weekday (Monday to Friday), d weekend (Saturday and Sunday), e daytime (dawn to dusk), f nighttime (dusk to dawn) 
(a) Summer

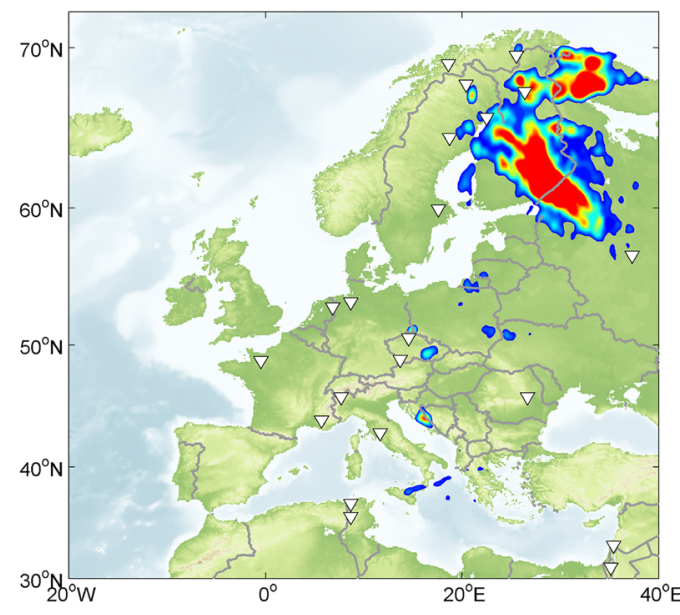

(b) Winter

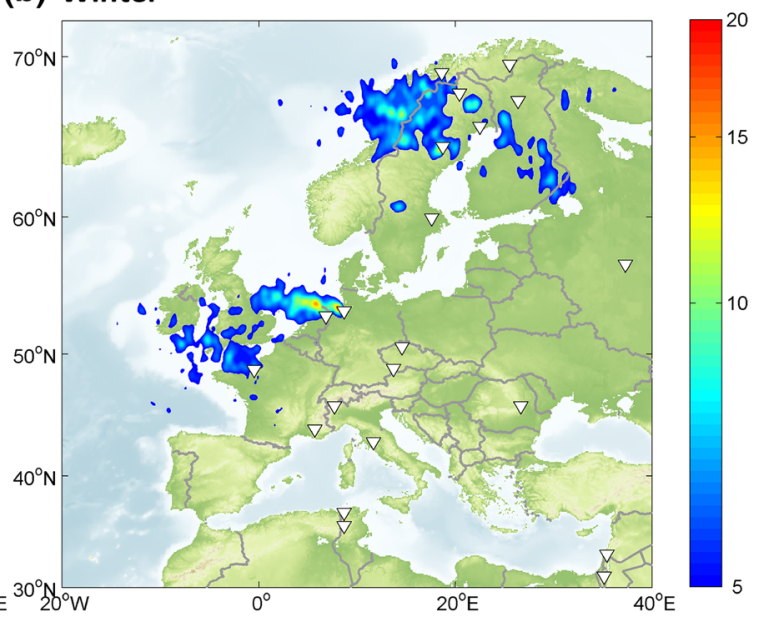

\section{(c) Weekday}

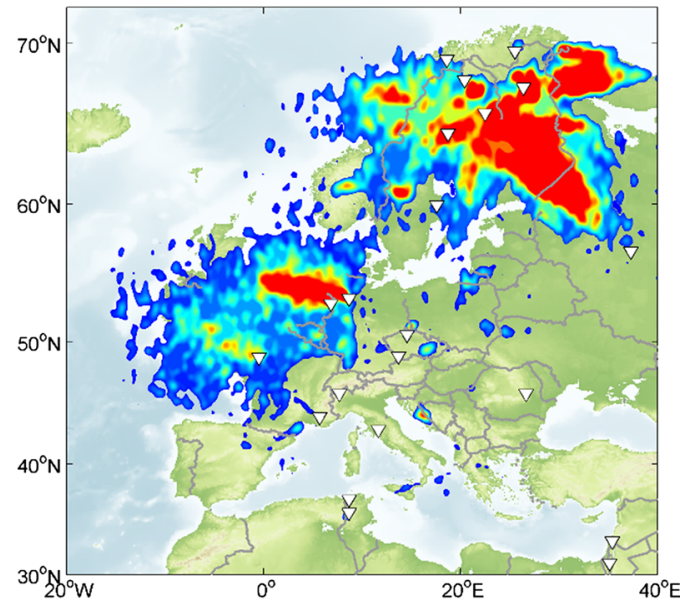

(d) Weekend

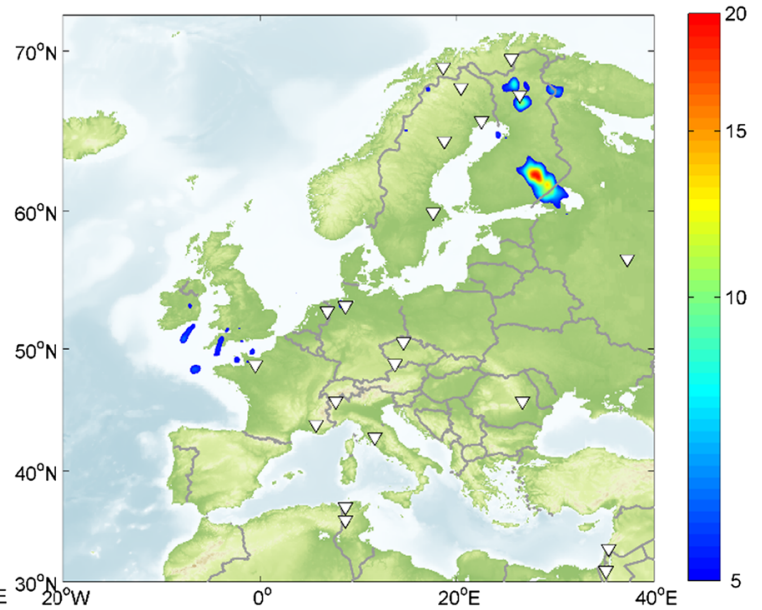

(e) Daytime

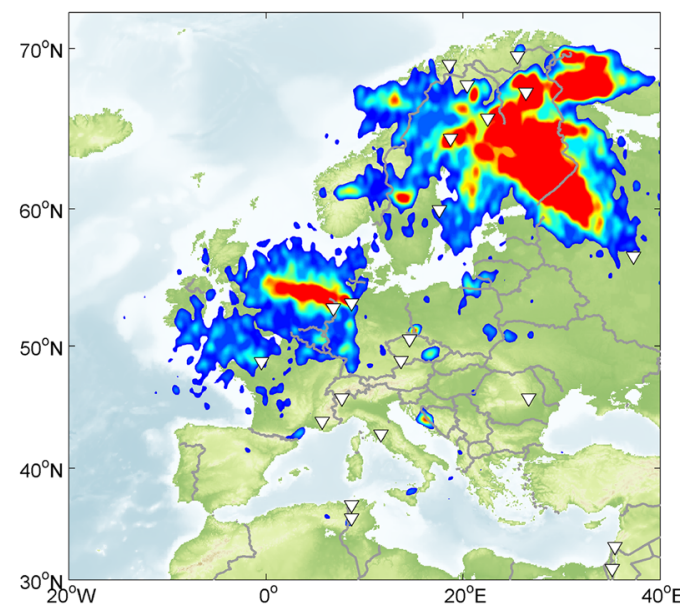

(f) Nighttime

Number of events

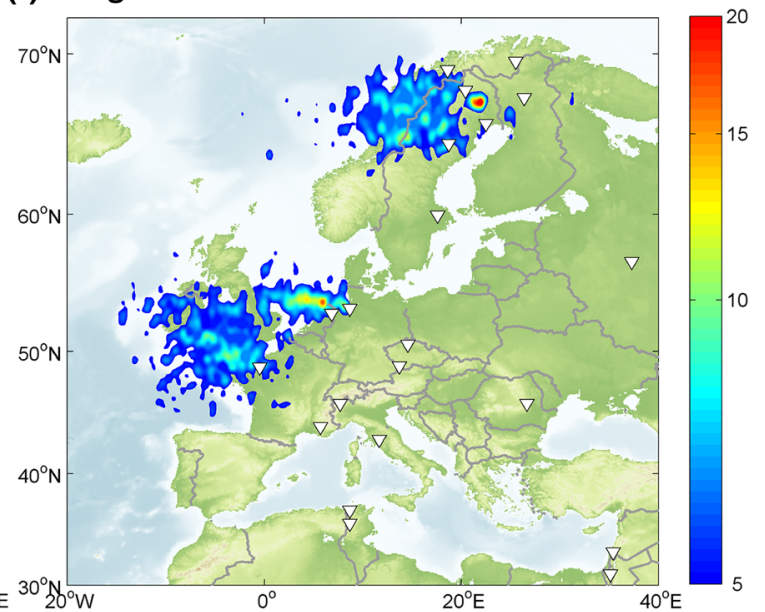




\subsection{Seasonal, Weekly and Diurnal Variation}

The variation of the observed infrasound sources due to season, weekday and daytime helps to identify parameters that have an effect on the detection capability of the infrasound stations and to characterize the anthropogenic origin of the sources. Figure 12 provides analyses of these variations shown by event number density maps as presented in Figs. 9 and 10. The scale of the color bars is adjusted to highlight lower threshold sources and variations between summer and winter, weekday and weekend, daytime and nighttime.

The semi-annual change of the stratospheric wind direction explains the clear seasonal variation in the detection of infrasound signals as shown in Fig. 12a, b. During summer, the prevailing direction for the stratospheric wind is westward and therefore infrasound arrays predominantly detect sources from the east (e.g., mining blasts and industrial activity in Northern and Eastern Europe, see Sect. 4.1). Furthermore, sporadic summertime activity of Etna volcano is recorded at the Tunisian stations west of the source (see Tailpied et al. 2013; Assink et al. 2014b). The cluster of locations from the Mt. Etna infrasound activity is elongated into a line from I48TN, in the same manner as in Fig. 11. This is due to cross winds for the south-to-north propagation path toward a second detecting and locating station, e.g., I26DE, leading to larger event-to-event uncertainties and thus differences in the back-azimuth resolution. During winter, the stratospheric wind reverses and dominantly blows eastward, so that infrasound arrays mainly detect sources from the west, e.g., sonic booms from supersonic flights taking place west of the European coasts. This dominant pattern is only interrupted due to sudden stratospheric warmings corresponding to temporary stratospheric wind reversals (see Assink et al. 2014a; Smets and Evers 2014). Comparing the seasonal distribution of infrasound activity with the study by Le Pichon et al. (2008), similar behavior can be observed for summertime event detections, while some differences show up during wintertime. These differences are mostly due to the fact that with IPLOR, I31KZ and I43RU stations are available in this study south to southeast of the seven stations of Le Pichon et al. (2008), which are also able to detect and locate wintertime events (e.g., in the Lake Ladoga region) farther to the east than in the previous study.

A weekly variation in the infrasound activity changing from strong activity during the week to almost no infrasound sources during the weekend as shown in Fig. 12c, d is a clear indication of a dominant anthropogenic origin (industrial activity and mining blasts only taking place on working days). Furthermore, most of the military activity and supersonic flights over the North Sea and Atlantic Ocean also take place during weekdays (as also found by Walker et al. (2011) for the Western USA), with the recognizable exception of infrasound signatures on the Concorde flight paths to London and Paris (Liszka and Waldemark 1995; Le Pichon et al. 2002) that were also observed on weekends until the end of operations in 2003. The lines in Figs. 9 as well as 12c, d (and also in Le Pichon et al. 2008) reflect to some degree the flight paths between New York and London/Paris, along which the sonic booms of many Concorde events occurred near the British/French coast.

The diurnal variation of infrasound source activity is another indicator of the anthropogenic origin of most of the events and it can furthermore be used to characterize nocturnal infrasound sources. While most of the sources are recorded during daytime (the hours between dawn and dusk at the source location, derived in this study from a sun cycle routine within the bulletin processing and filtering), reflecting the majority of industrial working hours, there are also a number of events recorded during nighttime as shown in Fig. 12e, f. These events are mostly located over the North Sea and Norwegian Sea and are most likely due to offshore supersonic flights that also take place during the night. Furthermore, it has to be considered that independent of the human working hours, there is nighttime at higher latitudes for nearly $24 \mathrm{~h}$ in winter, e.g., for the highest latitude cluster of events over north-western Norway and the Norwegian Sea in Fig. 12b, f (the definition of nighttime is treated differently compared to Le Pichon et al. 2008). 


\subsection{Station Configurations and Filtering}

Considering different station subsets and the application of distinct detection filters helps to highlight infrasound activity in certain regions and identify specific sources. It furthermore allows an increase in the accuracy of event localization with a reduced number of erroneous locations and less widely distributed event regions, when, e.g., restricting event localization to certain station combinations or excluding findings from other combinations.

The network geometry and station distribution related to a source region of interest has a strong impact on the localization accuracy. Source regions like the Lake Ladoga and North Sea areas show infrasound activity over a large spatial extent, although they might be due to specific sources of much smaller extent. An infrasound event outside of a network of stations, such that it is observed from almost the same back-azimuth by all stations, will be located with more uncertainty than an event within the network of stations observed from many different directions. The former is oftentimes the case within this study for Russian sources located by using Fennoscandian stations (Swedish stations only in the early years of the bulletin). The latter is more often the case using the globally distributed stations of the IMS network during later years (see Sect. 4.1), although both cases of events within and outside the network occur for the IMS. Furthermore the seasonal nature of the detections (see Sect. 4.2) may complicate the precise localization and also the type of events, since a larger spatial extent of detections may be due to moving sources as well.

A selection of a subset of stations that are required to define the location of infrasound activity in a certain region of interest helps to avoid imprecise localization contributions from very remote stations and focuses on the accuracy of estimating source coordinates instead of increasing detection numbers. Figure 13a, for example, shows the more constrained location of North Sea infrasound activity most likely associated with military supersonic aircrafts (Nippress and Green 2017) by considering only detections that include at least two of the nearby stations FLERS (France), DBN (Netherlands) and IGADE (Germany). Compared with the elongated North Sea source regions as shown in Fig. 9, the source region becomes more constrained. The former, stretched source region is mostly due to combining I26DE detections with either IGADE or DBN detections, resulting in cross bearings by two stations that are nearly on the same line toward the source region, thereby increasing the location uncertainty. The latter, more precise source location identifies a source region for infrasound signatures outside the offshore Dutch frontier nearby the largest Dutch air force training area "De Vliehors". Nevertheless, it is possible that due to the above-mentioned choice of the station subset, a number of true source detections, e.g., by the British Royal Air Force and more toward the coast of Great Britain, become disregarded in Fig. 13a. This can also be concluded when comparing Figs. 9 and 13a with the IDC LEB events in Fig. 11, where the cluster of North Sea sources of infrasound is also more wide stretched. It might be the case that using FLERS to the southwest of the events and another station to the southeast requires propagation along and against the prevailing stratospheric wind and restricts the detections too much.

The application of a time filter is presented in Fig. 13b, only highlighting source activity between 2012 and 2014 (the ARISE project duration) in the Mediterranean region. In contrast to Fig. 9, which focuses on the large number of detections in Northern Europe over many years, this figure allows to point out regions of infrasound activity in Southern France, Croatia, Tunisia and near the Italian volcano Mt. Etna. They are recorded by infrasound arrays in this region, which were only installed or in operation within the given ARISE project duration (and by surrounding stations in Southern Germany, Czech Republic, Romania and Israel). Sources of military or industrial activity are well identified and located by this method; furthermore, the detection by at least two stations of the high-frequency infrasound activity of Etna volcano during phases of eruptive activity is recognizable for periods in summer 2012 and during a sudden stratospheric warming event in January 2013 (Tailpied et al. 2017). 

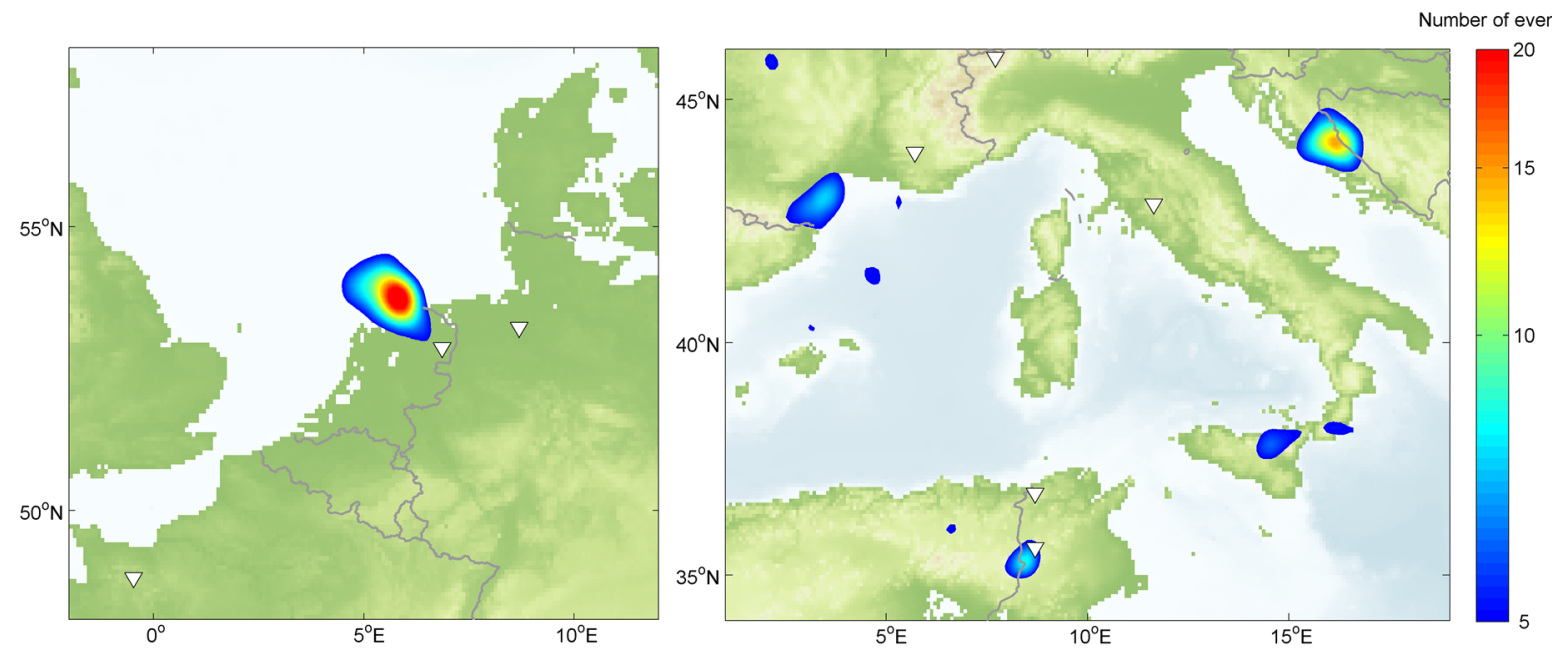

Figure 13

Zoomed and filtered infrasound source activity: (left) for the North Sea source area, using only detections with at least two of the shown stations FLERS (France), DBN (Netherlands) and IGADE (Germany); (right) for the Mediterranean source area, using only detections from the ARISE project duration (2012-2014)

\section{Conclusions and Outlook}

The analysis of infrasound recordings of up to 16 years of data taken by 24 different stations allowed the detection and localization of about 48,000 European infrasound events within this study. The use of a dense network of infrasound stations in Europe compared to the far more sparse distribution of IMS stations in this area provided important insights into detection and location capability and corresponding event identification. Furthermore, a detailed comparison with a previous investigation using only seven infrasound arrays in Europe was drawn in this study. The increased number of stations allowed the detection of a larger number of events and identification of a larger number of sources compared with the use of the IMS stations alone, e.g., seen in the Fennoscandian region. The accuracy of the event location estimates depends on the locations of the stations detecting the events and the accuracy of the directional estimates made.

For events detected by stations with a large number of elements located at a range of different angles to the source, event origins are more precise and the source regions are more sharply defined. However, for stations with higher uncertainties, e.g., due to the availability of only three elements in a small aperture and/or detecting events in nearly parallel directions, event locations are more approximate or even erroneous and source regions less well defined. Comparisons within this study to groundtruth information and LEB data illustrated both cases, depending on the given source region, available station recordings and event-dependent propagation conditions.

Investigation of the seasonal variation of source detections shows which source regions in Europe are identified in station recordings during which season, and when the sensitivity of stations is higher or lower due to the prevailing direction of stratospheric winds. These findings were strongly supported by using ECMWF profiles for the realistic and event-dependent quantification of atmospheric conditions; a relocation with propagation modeling based on ECMWF profiles improved the detection and location of source regions. Furthermore, the quantification of diurnal and weekly variations in the detected events allowed the identification of repeating man-made infrasound (by industrial, military and aviation activities) in several source regions.

Through estimating the performance of the previous and current network of infrasound stations in Europe, as in the course of the ARISE infrastructure project, and as shown in this study, it is clear that a 
higher number of infrasound stations of good quality within Europe increases the potential to reliably identify and precisely locate infrasound events. The detection and location capability of infrasonic events can be improved by a denser and more uniformly distributed network of stations in the context of studies for atmospheric dynamics as well as in the context of CTBT verification. It can also be improved by an optimization of station geometry, especially by adding elements to three-instrument arrays and enlarging their aperture. More data from such infrasound arrays would clearly improve the capability of quantifying variations in infrasonic source activity and estimate the origin of more infrasound events.

\section{Acknowledgements}

The research leading to these results was performed within the ARISE2 project (http://arise-project.eu/, last access March 2018) and received funding from the European Community's Horizon 2020 programme under grant agreement 653980. The complete dataset of the European Infrasound Bulletin described and presented within this study is available on the ARISE data portal (http://arise-portal.eu). The Swedish-Finnish Infrasound Network is operated by the Swedish Institute of Space Physics in collaboration with University of Oulu, Sodankylä Geophysical Observatory, Finland.

Open Access This article is distributed under the terms of the Creative Commons Attribution 4.0 International License (http:// creativecommons.org/licenses/by/4.0/), which permits unrestricted use, distribution, and reproduction in any medium, provided you give appropriate credit to the original author(s) and the source, provide a link to the Creative Commons license, and indicate if changes were made.

\section{REFERENCES}

Assink, J. D., Le Pichon, A., Blanc, E., Kallel, M., \& Khemiri, L. (2014a). Evaluation of wind and temperature profiles from ECMWF analysis on two hemispheres using volcanic infrasound. Journal of Geophysical Research Atmosphere. https://doi.org/10. 1002/2014JD021632.

Assink, J. D., Waxler, R., Smets, P., \& Evers, L. G. (2014b). Bidirectional infrasonic ducts associated with sudden stratospheric warming events. Journal of Geophysical Research Atmosphere. https://doi.org/10.1002/2013JD021062.
Brachet, N., D. Brown, R. Le Bras, Y. Cansi, P. Mialle, and J. Coyne (2010), Monitoring the Earth's atmosphere with the global IMS infrasound network, in: Le Pichon, A., E. Blanc, and A. Hauchecorne (Eds.), Infrasound Monitoring for Atmospheric Studies, Springer, Heidelberg, Germany. ISBN:978-1-40209507-8

Brown, D. J., Katz, C. N., Le Bras, R., Flanagan, M. P., Wang, J., \& Gault, A. K. (2002). Infrasonic signal detection and source location at the Prototype International Data Center. Pure and Applied Geophysics. https://doi.org/10.1007/s00024-002-8674-2.

Campus, P. and D. Christie (2010), Worldwide observations of infrasonic waves, in: Le Pichon, A., E. Blanc, and A. Hauchecorne (Eds.), Infrasound Monitoring for Atmospheric Studies, Springer, Heidelberg, Germany. ISBN:978-1-4020-9507-8

Cansi, Y. (1995). An automatic seismic event processing for detection and location: the PMCC method. Geophysical Research Letters. https://doi.org/10.1029/95GL00468.

Ceranna, L., Le Pichon, A., Green, D. N., \& Mialle, P. (2009). The Buncefield explosion: a benchmark for infrasound analysis across Central Europe. Geophysical Journal International. https://doi.org/10.1111/j.1365-246X.2008.03998.x.

Christie, D. and P. Campus (2010), The IMS infrasound network: design and establishment of infrasound stations, in: Le Pichon, A., E. Blanc, and A. Hauchecorne (Eds.), Infrasound Monitoring for Atmospheric Studies, Springer, Heidelberg, Germany. ISBN:978-1-4020-9507-8

Coleman, T. F., \& Li, Y. (1996). An interior, trust region approach for nonlinear minimization subject to bounds. SIAM Journal on Optimization. https://doi.org/10.1137/0806023.

Drob, D. P., Picone, J. M., \& Garcés, M. A. (2003). Global morphology of infrasound propagation. Journal of Geophysical Research. https://doi.org/10.1029/2002JD003307.

Drob, D. P., et al. (2008). An empirical model of the Earth's horizontal wind fields: HWM07. Journal of Geophysical Research. https://doi.org/10.1029/2008JA013668.

Evers, L. G., \& Haak, H. W. (2001). Listening to sounds from an exploding meteor and oceanic waves. Geophysical Research Letters. https://doi.org/10.1029/2000GL011859.

Evers, L. G., \& Schweitzer, J. (2011). A climatology of infrasound detections in northern Norway at the experimental ARCI array. Journal of Seismology. https://doi.org/10.1007/s10950-0119237-8.

Garcés, M. A. (2013). On infrasound standards, part 1: time, frequency, and energy scaling. InfraMatics. https://doi.org/10.4236/ inframatics.2013.22002.

Garcés, M., Hansen, R. A., \& Lindquist, K. G. (1998). Traveltimes for infrasonic waves propagating in a stratified atmosphere. Geophysical Journal International. https://doi.org/10.1046/j. 1365-246X.1998.00618.x.

Garcés, M. A., Willis, M., Hetzer, C., Le Pichon, A., \& Drob, D. (2004). On using ocean swells for continuous infrasonic measurement of winds and temperature in the lower, middle, and upper atmosphere. Geophysical Research Letters. https://doi.org/ 10.1029/2004GL020696.

Ghica, D. V., Grecu, B., Popa, M., \& Radulian, M. (2016). Identification of blasting sources in the Dobrogea seismogenic region, Romania using seismo-acoustic signals. Physics and Chemistry of the Earth. https://doi.org/10.1016/j.pce.2016.04.006.

Gibbons, S. J., Asming, V., Eliasson, L., Fedorov, A., Fyen, J., Kero, J., et al. (2015a). The European Arctic: a laboratory for 
seismoacoustic studies. Seismological Research Letters. https:// doi.org/10.1785/0220140230.

Gibbons, S. J., Kværna, T., \& Mykkeltveit, S. (2015b). Could the IMS infrasound stations support a global network of small aperture seismic arrays? Seismological Research Letters. https:// doi.org/10.1785/0220150068.

Hedlin, M. A. H., Walker, K. T., Drob, D. P., \& de Groot-Hedlin, C. D. (2012). Infrasound: connecting the solid earth, oceans, and atmosphere. Annual Review of Earth and Planetary Sciences. https://doi.org/10.1146/annurev-earth-042711-105508.

Le Pichon, A., Assink, J. D., Heinrich, P., Blanc, E., CharltonPerez, A., Lee, C. F., et al. (2015). Comparison of co-located independent ground-based middle atmospheric wind and temperature measurements with numerical weather prediction models. Journal of Geophysical Research Atmosphere. https:// doi.org/10.1002/2015JD023273.

Le Pichon, A., Blanc, E., \& Drob, D. (2005). Probing high altitude winds using infrasound. Journal of Geophysical Research, 110, D20. https://doi.org/10.1029/2005JD006020.

Le Pichon, A., Ceranna, L., Pilger, C., Mialle, P., Brown, D., Herry, P., et al. (2013). The 2013 Russian fireball largest ever detected by CTBTO infrasound sensors. Geophysical Research Letters. https://doi.org/10.1002/grl.50619.

Le Pichon, A., Garcés, M., Blanc, E., Barthélémy, M., \& Drob, D. P. (2002). Acoustic propagation and atmosphere characteristics derived from infrasonic waves generated by the Concorde. Journal of the Acoustical Society of America. https://doi.org/10. 1121/1.1404434.

Le Pichon, A., Matoza, R., Brachet, N., \& Cansi, Y. (2010). Recent enhancements of the PMCC infrasound signal detector. InfraMatics, 26, 5-8.

Le Pichon, A., Vergoz, J., Herry, P., \& Ceranna, L. (2008). Analyzing the detection capability of infrasound arrays in Central Europe. Journal of Geophysical Research, 113, D12115. https:// doi.org/10.1029/2007JD009509.

Liszka, L., \& Waldemark, K. (1995). High resolution observations of infrasound generated by the supersonic flights of Concorde. Journal of Low Frequency Noise, Vibration and Active Control. https://doi.org/10.1177/026309239501400403.

Marchetti, E., Ripepe, M., Delle Donne, D., Genco, R., Finizola, A., \& Garaebiti, E. (2013). Blast waves from violent explosive activity at Yasur Volcano, Vanuatu. Geophysical Research Leters. https://doi.org/10.1002/2013GL057900.

Matoza, R. S., Vergoz, J., Le Pichon, A., Ceranna, L., Green, D. N., Evers, L. G., et al. (2011). Long-range acoustic observations of the Eyjafjallajökull eruption, Iceland, April-May 2010. Geophysical Research Letters, 38, L06308. https://doi.org/10.1029/ 2011 GL047019.

Mc Laughlin, K. L., A. Gault, D. J. Brown (2000), Infrasound detection of rocket launches, Report from Proceedings of the 22nd Annual DoD/DOE Seismic Research Symposium, p 12

Negraru, P. T., Golden, P., \& Herrin, E. T. (2010). Infrasound propagation in the 'zone of silence'. Seismological Research Letters. https://doi.org/10.1785/gssrl.81.4.614.

Nippress, A., \& Green, D. N. (2017). Sensitivity of the International Monitoring System infrasound network to elevated sources: a western Eurasia case study. Geophysical Journal International. https://doi.org/10.1093/gji/ggx342.

Olson, J. V. (2004). Infrasound signal detection using the Fisher F-Statistic. InfraMatics, 06, 1-7.

Picone, J. M., Hedin, A. E., Drob, D. P., \& Aikin, A. C. (2002). NRLMSISE-00 Empirical model of the atmosphere: statistical comparisons and scientific issues. Journal of Geophysical Research. https://doi.org/10.1029/2002JA009430.

Pilger, C., \& Ceranna, L. (2017). The influence of periodic wind turbine noise on infrasound array measurements. Journal of Sound and Vibration. https://doi.org/10.1016/j.jsv.2016.10.027.

Pilger, C., Ceranna, L., Ross, J. O., Le Pichon, A., Mialle, P., \& Garcés, M. A. (2015). CTBT infrasound network performance to detect the 2013 Russian fireball event. Geophysical Research Letters. https://doi.org/10.1002/2015GL063482.

Pilger, C., Streicher, F., Ceranna, L., \& Koch, K. (2013). Application of propagation modeling to verify and discriminate ground-truth infrasound signals at regional distances. InfraMatics. https://doi.org/10.4236/inframatics.2013.24004.

Ponceau, D. and L. Bosca (2010), Low-noise broadband microbarometers, in: Le Pichon, A., E. Blanc, and A. Hauchecorne (Eds.), Infrasound Monitoring for Atmospheric Studies, Springer, Heidelberg, Germany. ISBN:978-1-4020-9507-8

Sindelarova, T., Buresova, D., Chum, J., \& Hruska, F. (2009). Doppler observations of infrasonic waves of meteorological origin at ionospheric heights. Advances in Space Research. https://doi.org/10.1016/j.asr.2008.08.022.

Smets, P. S. M., Assink, J. D., Le Pichon, A., \& Evers, L. G. (2016). ECMWF SSW forecast evaluation using infrasound. Journal of Geophysical Research Atmosphere. https://doi.org/10. 1002/2015JD024251.

Smets, P. S. M., \& Evers, L. G. (2014). The life cycle of a sudden stratospheric warming from infrasonic ambient noise observations. Journal of Geophysical Research Atmosphere. https://doi. org/10.1002/2014JD021905.

Stevens, J. L., Divnov, I. I., Adams, D. A., Murphy, J. R., \& Bourchik, V. N. (2002). Constraints on infrasound scaling and attenuation relations from Soviet explosion data. Pure and Applied Geophysics. https://doi.org/10.1007/s00024-002-8672.

Tailpied, D., Le Pichon, A., Marchetti, E., Assink, J., \& Vergniolle, S. (2017). Assessing and optimizing the performance of infrasound networks to monitor volcanic eruptions. Geophysical Journal International. https://doi.org/10.1093/gji/ggw400.

Tailpied, D., Le Pichon, A., Marchetti, E., Ripepe, M., Ceranna, L., \& Brachet, N. (2013). Remote infrasound monitoring of Mount Etna: observed and predicted network detection capability. InfraMatics. https://doi.org/10.4236/inframatics.2013.

Walker, K. T. and M. A. H. Hedlin (2010), A review of wind-noise reduction methodologies, in: Le Pichon, A., E. Blanc, and A. Hauchecorne (Eds.), Infrasound Monitoring for Atmospheric Studies, Springer, Heidelberg, Germany. ISBN:978-1-40209507-8

Walker, K. T., Shelby, R., Hedlin, M. A. H., de Groot-Hedlin, C., \& Vernon, F. (2011). Western U.S. infrasonic catalog: illuminating infrasonic hot spots with the USArray. Journal of Geophysical Research. https://doi.org/10.1029/2011JB008579. 